\title{
Considerations for Building the Business Cases for Bidirectional Electric Vehicle Charging
}

\author{
Energy Systems Division
}




\section{About Argonne National Laboratory}

Argonne is a U.S. Department of Energy laboratory managed by UChicago Argonne, LLC under contract DE-AC02-06CH11357. The Laboratory's main facility is outside Chicago, at 9700 South Cass Avenue, Lemont, Illinois 60439. For information about Argonne and its pioneering science and technology programs, see www.anl.gov.

\section{DOCUMENT AVAILABILITY}

Online Access: U.S. Department of Energy (DOE) reports produced after 1991 and a growing number of pre-1991 documents are available free at OSTI.GOV (http://www.osti.gov/),

a service of the US Dept. of Energy's Office of Scientific and Technical Information.

\section{Reports not in digital format may be purchased by the public} from the National Technical Information Service (NTIS):

U.S. Department of Commerce

National Technical Information Service

5301 Shawnee Road

Alexandria, VA22312

www.ntis.gov

Phone: (800) 553-NTIS (6847) or (703) 605-6000

Fax: (703) 605-6900

Email: orders@ntis.gov

Reports not in digital format are available to DOE and DOE contractors from the Office of Scientific and Technical Information (OSTI):

U.S. Department of Energy

Office of Scientific and Technical Information

P.O. Box 62

Oak Ridge, TN 37831-0062

www.osti.gov

Phone: (865) 576-8401

Fax: (865) 576-5728

Email: reports@osti.gov

\section{Disclaimer}

This report was prepared as an account of work sponsored by an agency of the United States Government. Neither the United States Government nor any agency thereof, nor UChicago Argonne, LLC, nor any of their employees or officers, makes any warranty, express or implied, or assumes any legal liability or responsibility for the accuracy, completeness, or usefulness of any information, apparatus, product, or process disclosed, or represents that its use would not infringe privately owned rights. Reference herein to any specific commercial product, process, or service by trade name, trademark, manufacturer, or otherwise, does not necessarily constitute or imply its endorsement, recommendation, or favoring by the United States Government or any agency thereof. The views and opinions of document authors expressed herein do not necessarily state or reflect those of the United States Government or any agency thereof, Argonne National Laboratory, or UChicago Argonne, LLC. 
ANL/ESD-21/8

\section{Considerations for Building the Business Cases for Bidirectional Electric Vehicle Charging}

Yan Zhou, Ralph T. Muehleisen and Zhi Zhou

Energy Systems Division, Argonne National Laboratory

Charles Macal

Decision Infrastructure Sciences, Argonne National Laboratory

Rima Oueid

Office of Technologies Transitions, U.S. Department of Energy

August 2021 



\section{CONTENTS}

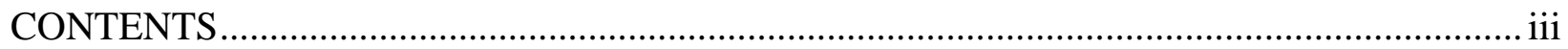

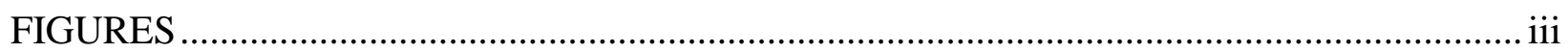

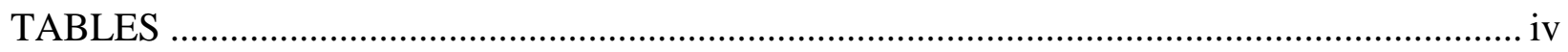

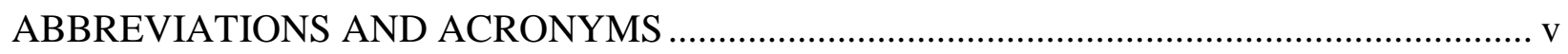

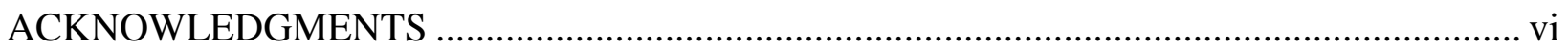

EXECUTIVE SUMMARY ………………………...................................................... vii

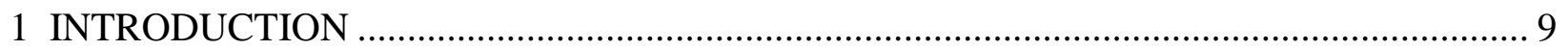

2 BIDIRECTIONAL ELECTRIC VEHICLE AND CHARGING FRAMEWORK …………...... 11

2.1 State of the Art in Bidirectional Electric Vehicles.......................................................... 12

2.2 Consumers' Perspective: Why Do Consumers Need To Be Incentivized? …………..... 18

2.2.1 Light-Duty Vehicle Owners............................................................................. 18

2.2.2 Opportunities for Medium- and Heavy-Duty Vehicles ....................................... 21

2.2.3 Research and Standard Needs ..................................................................... 22

2.3 Commercial Building Owners' Perspective: How CAN Buildings Benefit from BDEVs and Share the Benefits with BDEV Owners? ........................................................... 22

2.3.1 Benefits of BDEVs over Stationary Storage inside Buildings............................ 24

2.3.2 Peak Shaving and Demand Charge Reduction .................................................... 24

2.3.3 BDEVs as Battery Backup to Buildings ............................................................ 26

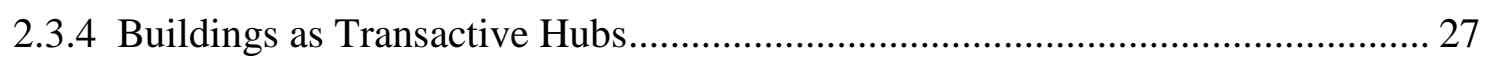

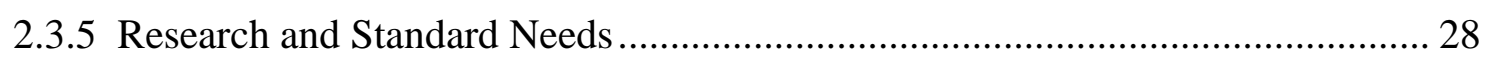

2.4 Utility Perspective: Where and How to Incentivize …………………………............ 28

2.4.1 Mobility Revolution Has Significant Impacts on the Grid ................................. 28

2.4.2 Impact on Transmission and Distribution Grid ................................................ 30

2.4.3 Research and Standard Needs ...................................................................... 32

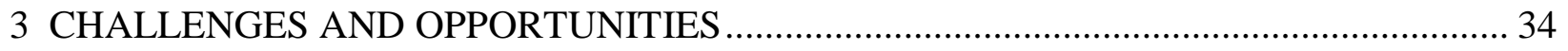

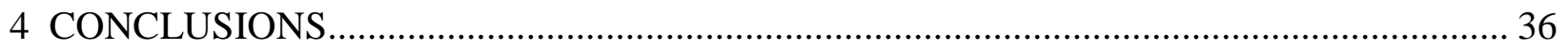

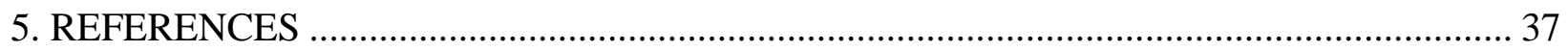

\section{FIGURES}

1 Bidirectional Electric Vehicle and Charging Framework ..................................................... 11 
2 15-year per-mile Cost of Driving a MY 2020 Small SUV ……………............................... 19

3 15-year per-Mile Cost of Driving a MY 2025 Small SUV, Including Bidirectional or

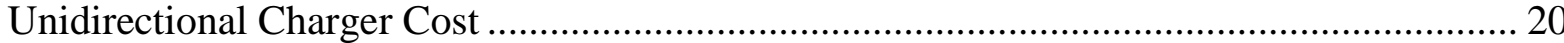

4 Value Streams of Building-Connected Energy Storage to Building Owners and the Grid .... 23

5 Use of BEVs to Provide Peak Shaving and Demand Control to a Building........................... 25

6 Maximum Demand Charges across the United States ............................................................ 26

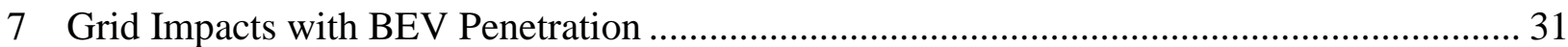

\section{TABLES}

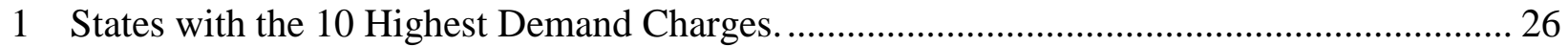

2 Capital Costs for a Building Owner to Install 3 MWh of Storage ............................................ 27

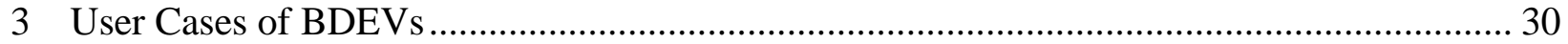




\section{ABBREVIATIONS AND ACRONYMS}

$\mathrm{AC}$

alternating current

BDEV

bidirectional battery electric vehicle

BEV

BEV200

battery electric vehicle

BEV300

battery electric vehicle with an electric range of 200 miles

battery electric vehicle with an electric range of 300 miles

DC

direct current

DCFC

DER

direct current fast charging

DOE

distributed energy resource

DSO

Department of Energy

distribution system operator

EVSE

electric vehicle supply equipment

FERC

Federal Energy Regulatory Commission

ICE

internal combustion engine

IEA

International Energy Agency

$\mathrm{kWh}$

kilowatt-hour(s)

MY

model year

PEV

plug-in electric vehicle

PHEV

plug-in hybrid electric vehicle

SUV sports utility vehicle

TCO total cost of ownership

UL Underwriters Laboratory

V2B

V2G

$\mathrm{V} 2 \mathrm{H}$

vehicle-to-building

vehicle-to-grid

vehicle-to-home

V2L

vehicle-to-microgrid or vehicle-to-load

V2X

vehicle-to-everything (V2X) 


\section{ACKNOWLEDGMENTS}

The efforts of all the authors from Argonne National Laboratory (under Contract DEAC02-06CH11357) are supported by the U.S. Department of Energy's Office of Technologies Transitions (OTT). The authors would like to thank Marcos Harsha Gonzales of OTT for his continued support of this project. The authors thank Luke Rush and David Gohlke of Argonne National Laboratory for helpful discussion and their assistance with analysis. The authors also thank Lee Slezak (Vehicles Technology Office), Chris Irwin (Office of Electricity), and Dan Ton (Office of Electricity) of DOE for reviewing the report and providing valuable comments. 


\section{EXECUTIVE SUMMARY}

The purpose of this report is to serve as an informative discussion document and to consider perspectives of some key stakeholders that affect commercialization of bi-directional electric vehicles (EVs), charging infrastructure, and other related technologies. In this report, we synthesized information from existing lab studies and a series of industry roundtables, panels, and webinars facilitated by the U.S. Department of Energy's (DOE's) Office of Technology Transitions, in collaboration with the DOE's Vehicles Technology Office and Argonne National Laboratory, aimed at discussing these technologies. This synthesis identifies key issues and considerations that factor into stakeholder perspectives and the business cases for potential stakeholder adoption of bidirectional electric vehicles, charging infrastructure, and other related technologies. Plug-in electric vehicle (PEV) owners, building owners, and grid operators all have the potential to develop business cases for bidirectional PEVs and the associated charging infrastructure. Bidirectionality includes the transfer of electricity or associated grid services from a vehicle to a home, building, grid, or other infrastructure, and vice versa also known as V2X).

This preliminary quantitative and qualitative analysis uses battery electric vehicles (BEVs) as an example, to help define key barriers in making the business case for bidirectional use of PEVs and charting the path forward for more rapid adoption. Note that vehicle manufactures, battery manufacturers, and potential aggregators of bidirectional PEVs also have relevant business cases. We briefly touch on them in this report, but they will require additional analysis to demonstrate business models; this is beyond the scope of this report. For example, Federal Energy Regulatory Commission (FERC) Order 2222 (18 CFR Part 35) allows utilities or third parties to aggregate distributed energy resources, such as bidirectional PEVs, to provide and monetize energy or grid services alongside traditional resources in wholesale markets.

For light-duty PEV owners, fuel only accounts for a small portion, around 5 to $7 \%$, of the levelized cost of driving per mile; therefore bidirectionality will not significantly affect the overall cost of ownership if it only reduces or eliminates fuel costs for the vehicle owner. Incentives or additional profits from selling the electricity back to a building or the grid are needed both to bring down the lifetime or per-mile cost of driving and to encourage the adoption of BEVs with bidirectionality. The relatively large batteries, duty cycles, predictable charging needs, and predictable charging locations of medium-duty vehicles (MDVs) and heavy-duty vehicles (HDVs) - especially buses and utility trucks - present a unique opportunity for bidirectional business cases. Bidirectionality could potentially create another revenue stream for fleet managers, which would significantly improve their return on investment in electrification. However, PEVs today are only capable of V2X when connected to direct current (DC) electric vehicle supply equipment (EVSE) since they do not have an on-board bidirectional converter that would allow them to export alternating current (AC). DC EVSE's are beginning to enter the market, however, additional analysis is needed to summarize and optimize state-of-the-art of bidirectional PEV charging capabilities that exist today for $\mathrm{V} 2 \mathrm{X}$ and analyze the operational aspects, especially dwell time and charging patterns to benefit all stakeholders involved.

This report describes two important opportunities where bidirectional PEVs could benefit building owners: peak shaving and battery backup. In both cases, bidirectional PEVs would serve as temporary electricity storage that costs less than permanent storage to provide resilience. 
The report also describes the interactions between bidirectional PEVs, associated charging infrastructure, and the power grid; potential business opportunities for stakeholders, including transmission/distribution system operators, wholesale/retail energy, and grid service market participants; and challenges involved in fully capturing these opportunities. It also identifies key research areas and areas of technology development that would facilitate adoption.

Complementary innovations in artificial intelligence, block chain, digitization and other areas, along with the right policies, access to energy markets, and business models, could help the business cases for bidirectional PEVs. These developments will enable the industry to flourish in the United States, while simultaneously accelerating electrification, utilizing renewables, reducing peak electricity demand, and providing resilience to the energy system. Because bidirectional PEVs serve dual purposes - transport and storage - they reduce the need for stationary storage in certain applications, which helps reduce the need for rare earth minerals needed in storage applications. This promotes sustainability and alleviates pressure on the supply chains for critical materials. An important consideration for all types of storage markets today.

This page left intentionally blank. 


\section{INTRODUCTION}

The International Energy Agency (IEA) conservatively estimates that there will be 130 million plug-in electric vehicles (PEVs) globally by 2030 (IEA 2019). PEVs include both battery electric vehicles (BEVs) and plug-in hybrid electric vehicles (PHEVs). IEA estimated that PEVs could contain 10 times the amount of energy storage needed by the grid if they are bidirectional (IEA 2019). (Bidirectional PEVs are defined in Section 2). According to the IEA's most aggressive estimate, there could be up to 250 million electric vehicles on the road within that time. This would mean the grid could meet all of its energy-storage needs using only $6 \%$ of batteries in the automotive fleet. However, current estimates assume half of these electric vehicles could be located in China alone. Europe has also recently accelerated its adoption of electric vehicles (EVs). Despite China and Europe's current leads, there is a convergence of innovations occurring that could help the United States catch up.

While PEVs have become a significant end-user of electricity, they also present potential disruptions to the electricity grid. Many managed charging options, both passive and active, have been explored by technology vendors, utilities and other service providers. Among these options, bidirectional charging has the potential to reshape the grid's overall load profile, and for PEVs to serve as energy storage for homes, buildings, and the grid, which would provide resilience benefits during emergencies and grid outages. However, the adoption of bidirectional charging presents many challenges in terms of technology, customer acceptance, and considerations for the development of appropriate business models, which is the focus of this report. In order to develop a viable business model, the technology and standards requirements, costs, and benefits for bidirectional charging must be balanced among the use cases for the primary stakeholders: vehicle manufacturers, vehicle owners, building owners, electricity utilities, and grid operators.

This report explores the issues and considerations that factor into the future business cases from the perspectives of three key stakeholders: PEV owners, building owners, and utilities/grid operators, assuming the required vehicle and charging technologies will be commercially available. The report only briefly discusses the perspective of the vehicle manufacturers in Section 3, and further evaluation is recommended. By helping to define and build the business cases for bidirectional PEVs and the associated charging infrastructure requirements, the path forward for more rapid bidirectional adoption will become clear.

This report also identifies several key research areas and needed technologies to enable and maximize the business cases. Complimentary innovations in artificial intelligence, block chain, digitization, and other areas could facilitate the rapid adoption of bidirectional charging technology. The convergence of these technologies, along with the right policies and business models, could help the PEV industry flourish in the United States, while simultaneously accelerating electrification, increasing the use of renewables, reducing peak demand, and contributing to energy reliability and resilience. Note that vehicle manufactures, battery manufacturers, and potential aggregators of bidirectional PEVs have relevant business cases. We touch on them in this report, but they will require additional analysis to demonstrate business models; this is beyond the scope of this report. PEVs today are only capable of V2X when connected to direct current (DC) electric vehicle supply equipment (EVSE) since they do not 
have an on-board bidirectional converter that would allow them to export alternating current (AC). DC EVSE's are beginning to enter the market, however, additional analysis is needed to summarize and optimize state-of-the-art of bidirectional PEV charging capabilities that exist today for V2X and analyze the operational aspects, especially dwell time and charging patterns to benefit all stakeholders involved. Moreover, V2X only makes sense when the PEV is plugged into the charger for a much longer time than is needed to charge (if charging is needed). For light duty PEVs this is predominantly when they are at home overnight and in some cases, to a lesser extent plugged into workplace charging during the day (depending on how much remain charge is needed to get home). 


\section{BIDIRECTIONAL ELECTRIC VEHICLE AND CHARGING FRAMEWORK}

Bidirectional PEV charging means that electricity from PEV charging can travel in both directions: from the charging station to the vehicle, or from the vehicle to the charging station. The interconnection point could be at a home (V2H), larger building (V2B), or microgrid/load (V2L) - or even directly to the grid itself (V2G), as long as the interconnected charger has the necessary components and software. Figure 1 shows the key components in the bidirectional PEV and charging framework. In contrast, one-way PEV chargers only allow electricity to flow from the electric grid to the PEV. When a PEV charges, alternating current (AC) electricity from the grid is converted to direct current (DC) electricity, which is required for use in the car's battery. This conversion is carried out by either the vehicle's own converter or a converter located in the electric vehicle supply equipment (EVSE), also known as the charging station. In order for a house, building, or the grid to use the energy stored in a PEV's battery, the DC electricity stored in the battery must be converted back to AC electricity.

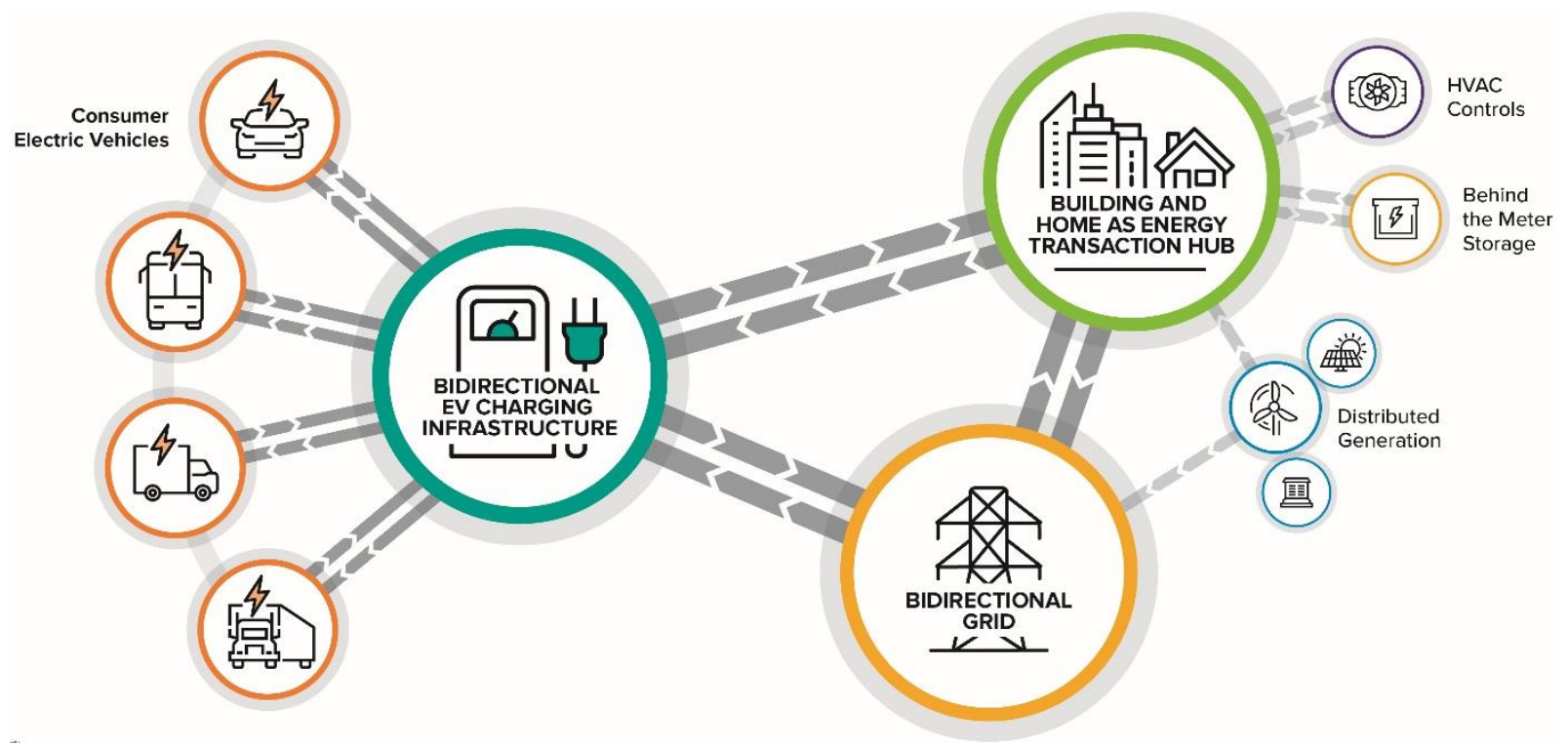

FIGURE 1 Bidirectional Electric Vehicle and Charging Framework

There are several major benefits of bidirectionality. First, it provides an emergency power source to the owner of the home or building where it is implemented. By using a bidirectional PEV charger, a vehicle can act as a source of energy (via its battery storage) during power outages or shortages. PEVs may provide an important energy source in times of emergency for homes or buildings that have been affected by power shortages or natural hazards. For example, Texans who were affected by the 2021 grid failure could have benefitted from a bidirectional connection from their vehicles to their homes (Traywick et al. 2021). Second, PEV owners with bidirectional chargers can save even more in operational costs and earn additional revenue by selling energy from the PEV battery back to the grid or to building owners to offset demand charges (see Section 2.3 and 2.4 for further discussion). Third, bidirectional PEV charging offers the owner of the home or building the opportunity to become energy self-sufficient, when 
combined with their own behind-the-meter energy resources, such as photovoltaic solar power generation. Last, utilities could leverage the stored energy in bidirectional PEVs to better manage residential or building loads, and to address critical energy peaks or access ancillary services.

\subsection{THE POTENTIAL FOR BIDIRECTIONAL ELECTRIC VEHICLE SERVICES, USE CASES \&DEMONSTRATION PROJECTS}

Bidirectional electric vehicles, through proper aggregation and with the appropriate enabling technologies (software and hardware), may be able to provide up to 13 different services originally identified for batteries as summarized in Figure 2 below (Fitzgerald et al. 2015)

\section{Customer Services (behind the meter for residences or buildings)}

- Backup Power - In the event of grid failure, energy storage paired with a local generator can provide backup power at multiple scales, ranging from second-to-second power quality maintenance for industrial operations to daily backup for residential customers (Fitzgerald et al., 2015).

- Increased PV Self-Consumption - Minimizing export of electricity generated by behind-the-meter photovoltaic (PV) systems to maximize the financial benefit of solar $\mathrm{PV}$ in areas with utility rate structures that are unfavorable to distributed PV (e.g., nonexport tariffs) (Fitzgerald et al., 2015).

- Demand Charge Reduction (applies to buildings or commercial properties) - Utilities apply demand charges based on the maximum amount of power a customer used in any interval (typically 15 minutes) during the billing cycle. Demand charges usually apply to commercial and industrial customers, who tend to have higher peak loads (i.e., peak power demand) than residential customers (Brown 2017).

- Time-of-Use Bill Management - By minimizing electricity purchases during peak electricity-consumption hours when time-of-use (TOU) rates are highest and shifting these purchase to periods of lower rates, behind-the-meter customers can use energy storage systems to reduce their bill (Fitzgerald et al., 2015).

\section{Utility Services}

- Distribution Deferral - Delaying, reducing the size of, or entirely avoiding utility investments in distribution system upgrades necessary to meet projected load growth on specific regions of the grid (Fitzgerald et al., 2015).

- Transmission Deferral - Delaying, reducing the size of, or entirely avoiding utility investments in transmission system upgrades necessary to meet projected load growth on specific regions of the grid (Fitzgerald et al., 2015).

- Transmission Congestion Relief - ISOs charge utilities to use congested transmission corridors during certain times of the day. Assets including energy storage can be deployed downstream of congested transmission corridors to discharge during congested periods and minimize congestion in the transmission system (Fitzgerald et al., 2015).

- Resource Adequacy - Instead of investing in new natural gas combustion turbines to meet generation requirements during peak electricity-consumption hours, grid operators and utilities can pay for other assets, including energy storage, to incrementally defer or 
reduce the need for new generation capacity and minimize the risk of overinvestment in that area (Fitzgerald et al., 2015).

\section{ISO/RTO Services}

- Energy Arbitrage - The purchase of wholesale electricity while the locational marginal price (LMP) of energy is low (typically during nighttime hours) and sale of electricity back to the wholesale market when LMPs are highest. Load following, which manages the difference between day-ahead scheduled generator output, actual generator output, and actual demand, is treated as a subset of energy arbitrage in this report (Fitzgerald et al., 2015).

- Spinning Reserve - sometimes referred to as synchronized reserves, are intended to help the system respond quickly to unplanned outages or other contingency events. Spinning reserves are provided by units that are online but are not generating at full capacity and can therefore increase their output quickly to provide additional capacity to the system (Zhou et al., 2016).

- Non-Spin Reserve - sometimes referred to as supplemental reserves, are also intended to help the system recover from unplanned contingencies. However, non-spinning reserves can also be provided by units that are offline so long as they are able to deliver output to a target level within a predefined period of time (typically less than 30 minutes) (Zhou et al., 2016).

- Frequency Regulation - used to constantly and automatically balance small fluctuations in supply and demand in real-time. Providers of regulation service must be able to respond to automatic generation control signals from the system operator and, in a matter of seconds, change their output accordingly (Zhou et al., 2016).

- Voltage Support - produces or absorbs reactive power. This service maintains a specific voltage level under a variety of operating conditions subject to the limitations of the resources stated reactive capability. Although voltage is expensive to manage at the distribution level, this service has yet to be monetized by providers and is typically provided without compensation. (NEMA 2016) Voltage support can be provided by units at the distribution level, especially for feeders with high penetrations of renewable generation.

- Black start - is the ability of a unit to start from a cold shutdown to delivering power without assistance from an external power system. Since many generation units require input energy to startup and begin operation, some power systems must maintain a black start capability so that they are able to restore operations in the event of a system-wide power outage. Such black start capability typically relies on small diesel generators or other forms of energy storage to provide the initial energy needed for startup. (Montoya, et al. 2013) 


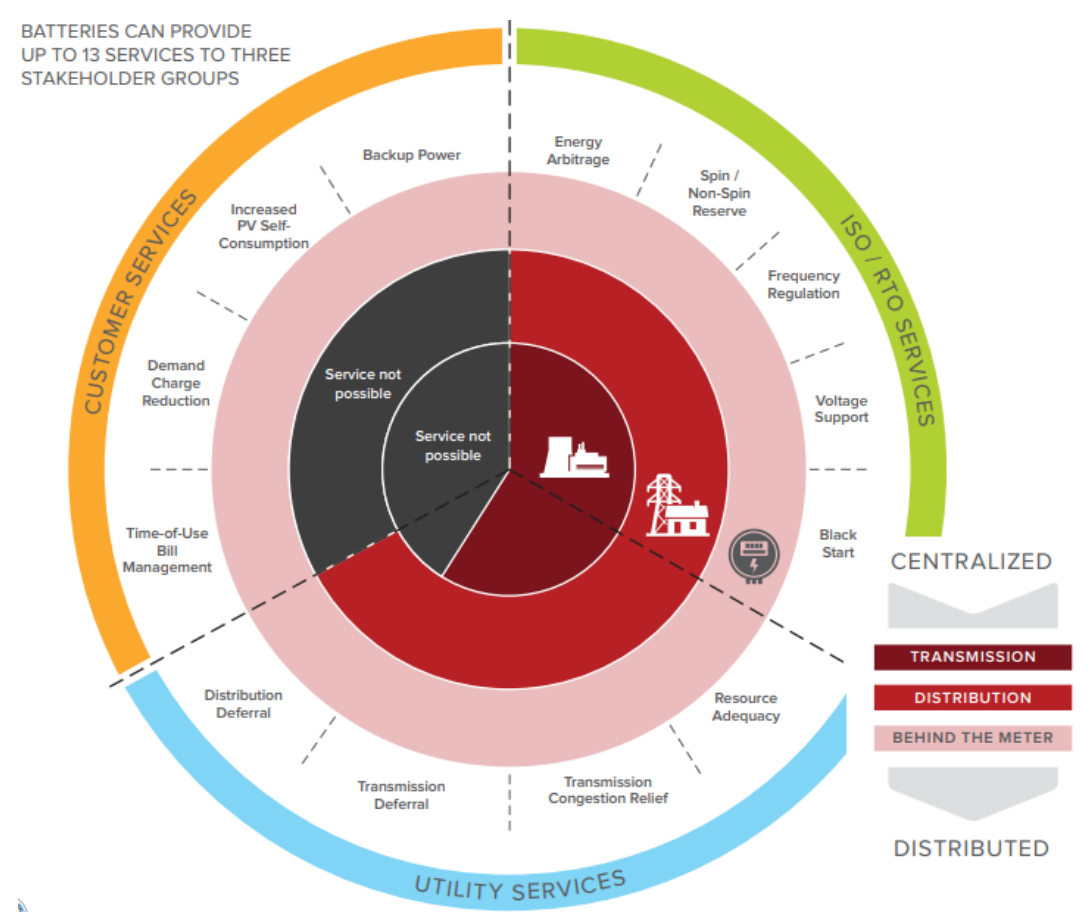

Figure 2 The Economics of Battery Energy Storage: How multi-use, customer-sited batteries deliver the most services and value to customers and the grid (Fitzgerald et al., 2015)

A relatively comprehensive list of $\mathrm{V} 1 \mathrm{X}$ and V2X use cases was developed by the California Vehicle to Grid Integration Working Group (SEPA 2020). Figure 3 illustrates the distribution of the potential participant sectors and applications for the V2X use cases. Although the report highlighted $80 \mathrm{~V} 2 \mathrm{X}$ use cases, $7 \mathrm{~V} 2 \mathrm{X}$ use cases in particular stood out and appear in at least one of the subsets for residential single-family homes and commercial workplaces for backup/resiliency, bill management, and renewable self-consumption (see figure and table below). Many of the $80 \mathrm{~V} 2 \mathrm{X}$ uses cases scored high for benefits, but most had higher costs and/or higher implementation risk. The $7 \mathrm{~V} 2 \mathrm{X}$ listed below specifically captures the sectors, applications, whether a single entity controlled the EV and the EVSE, and whether there is direct or indirect control of the EV and EVSE charging. It is worth highlighting that implementing use cases becomes harder when control is fragmented and indirect. In either case, additional analysis and demonstration for these use cases and others are warranted to analyze participant behavior, system performance/optimization, and potential value streams. This is particularly true from the perspective of the consumer (e.g. vehicle owner, aggregator, and commercial building owner such as a workplace) and the utility (includes distribution and transmission sectors). This document helps introduce and explore these stakeholder perspectives. 

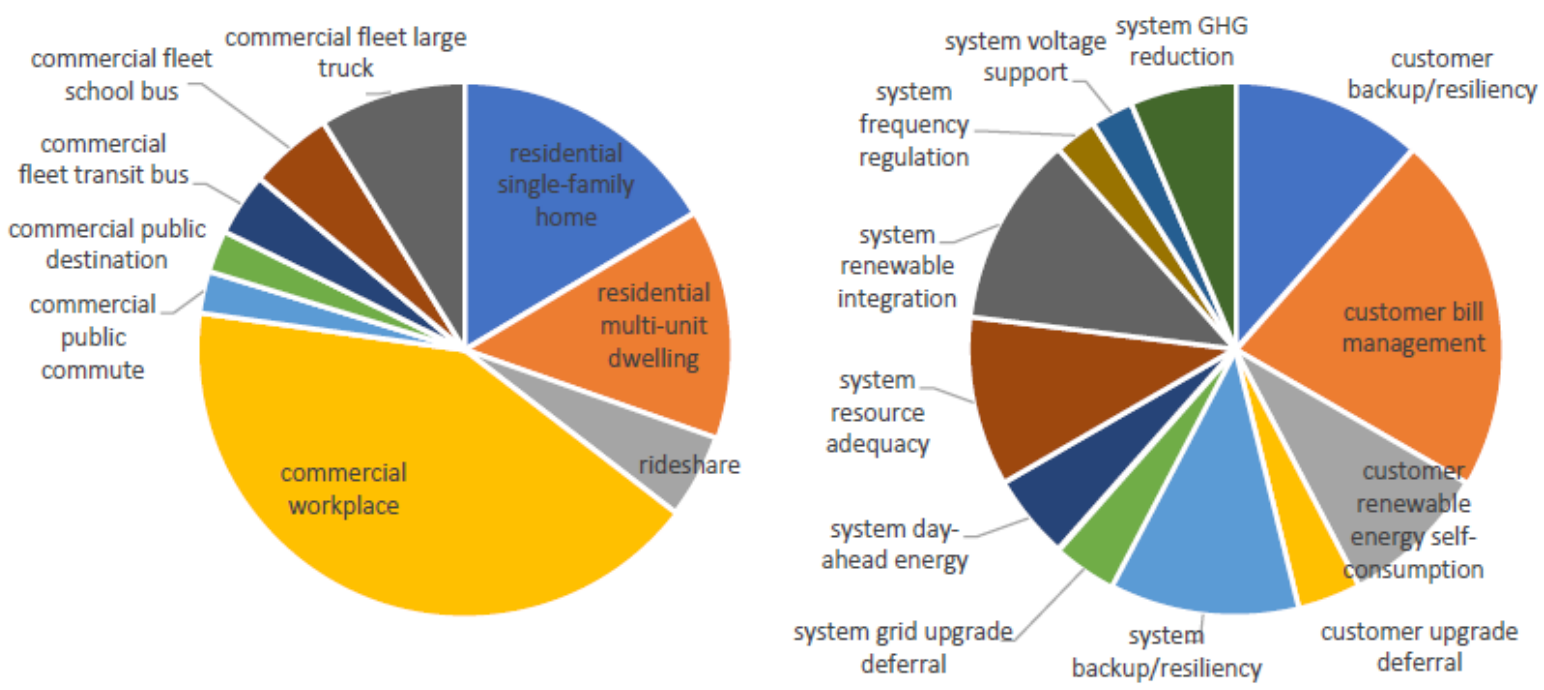

Figure 3 Sectors and Applications of All V2X Use Cases (Updated from, California Public Utility Commission 2020)

Table 1. V2X Use Cases Appearing in High-Scoring Subsets

\begin{tabular}{|l|l|l|l|}
\hline Sector & Application & $\begin{array}{l}\text { Indirect or Direct } \\
\text { Control of EV/EVSE }\end{array}$ & $\begin{array}{l}\text { Are EV/EVSE } \\
\text { Controlled by Single } \\
\text { Entity }\end{array}$ \\
\hline $\begin{array}{l}\text { Residential - Single } \\
\text { Family Home }\end{array}$ & $\begin{array}{l}\text { Single Family Home } \\
\text { Customer - Backup, } \\
\text { Resiliency }\end{array}$ & Indirect & Yes \\
\hline $\begin{array}{l}\text { Residential - Single } \\
\text { Family Home }\end{array}$ & $\begin{array}{l}\text { Single Family Home } \\
\text { Customer - Backup, } \\
\text { Resiliency }\end{array}$ & Direct & Yes \\
\hline $\begin{array}{l}\text { Commercial - Workplace } \\
\text { Customer }\end{array}$ & $\begin{array}{l}\text { Workplace Customer - } \\
\text { Bill Management }\end{array}$ & Direct & Yes \\
\hline $\begin{array}{l}\text { Commercial - Workplace } \\
\text { Customer }\end{array}$ & $\begin{array}{l}\text { Workplace Customer - } \\
\text { Backup, Resiliency }\end{array}$ & Direct & Yes \\
\hline $\begin{array}{l}\text { Commercial - Workplace } \\
\text { Customer }\end{array}$ & $\begin{array}{l}\text { Renewable Self- } \\
\text { Consumption }\end{array}$ & Indirect & No \\
\hline $\begin{array}{l}\text { Commercial - Workplace } \\
\text { Customer }\end{array}$ & Grid Upgrade Deferral & Indirect & No \\
\hline $\begin{array}{l}\text { Commercial - Fleet, } \\
\text { Large Truck (class 6-8) }\end{array}$ & $\begin{array}{l}\text { Customer - Bill } \\
\text { Management }\end{array}$ & Direct & Yes \\
\hline
\end{tabular}

Source: Adapted from FINAL REPORT OF THE CALIFORNIA JOINT AGENCIES VEHICLEGRID INTEGRATION WORKING GROUP, California Public Utility Commission, June 30, 2020 
Several bidirectional demonstration projects are in progress both across the United States and globally, but the technology is still in the earliest phases of commercialization (Briones et al. 2012; SEPA 2019; Ciampoli 2021). Currently, few EVSEs capable of bidirectional charging are available. The Nissan Leaf has a bidirectional charging capability to make it a backup storage system. Nissan has signed an agreement with Tokyo's Nerima Ward and the city of Yokosuka to provide bidirectional PEVs for emergency situations. Virta is a PEV charging platform operating in over 30 European countries with approximately 300 partners, and over 170,000 chargers deployed (Virta 2021). Virta works with utilities and businesses to deploy V2G hardware and software (Virta 2021). The company also provides financing and ongoing support to monetize V2G capabilities. Green Mountain Power (GMP) recently announced a bidirectional PEV program. GMP has installed a bidirectional charger operated by Fermata Energy (2020), a third-party V2G software system provider to charge fleet vehicles and use stored energy in bidirectional PEVs to help reduce peak energy use (GMP 2020). GMP will offer this option to businesses that are electrifying their car and bus fleets to help them manage their own peak demand and lower operational costs. Through peak shaving, GMP expects this program could reduce overall costs to ratepayers (GMP 2020). In Virginia, Dominion Energy is deploying 50 bidirectional electric school buses using Proterra's powertrains, batteries, and $60-\mathrm{kW}$ bidirectional DC chargers to demonstrate the business model of how V2G actually works in a real-world setting at a sizable scale (Dominion Energy 2020). Future analysis will need to consider the operational aspects, especially dwell time and charging patterns for different types of electric passenger and medium/heavy duty vehicles.

In addition, many energy companies and national governments are offering incentives (price reductions) to PEV drivers to encourage them to charge during off-peak hours when electricity is less expensive. Some energy companies now offer off-peak or "differential" energy tariffs to PEV owners: an owner may pay normal prices during the day, but cheaper rates for a certain number of hours during the evening and night. This can help balance load requirements on the grid and ensures that not all PEVs are charging during peak demand hours. If the electricity stored in a PEV were then used to power a house during the day, energy costs for the homeowner could be much cheaper than normal during those hours under the right conditions. Over time, this could result in significant reductions to a consumer's electricity bill. Some countries are introducing programs and incentives for individual PEV owners or fleet managers to do precisely this. For example, the demand side response scheme in the United Kingdom gives homeowners smart meters and empowers them to generate their own energy via onsite renewables (e.g., wind and solar photovoltaic power generation). It also enables them to feed excess energy back to the grid network. With the help of such schemes, together with other PEV and charging incentives across Europe, a home could become its own micro-power station in the near future.

This possibility applies not only to individual homes but also to larger apartment blocks, and even whole communities. While apartment block charging has traditionally been a problem for a number of reasons (83\% of house owners state that they charge at home, whereas only $13 \%$ of residents in apartment buildings say the same) energy self-sufficiency may help to solve this problem by pooling energy resources of residents in a more centralized way. For instance, schemes like the Brooklyn Micro-grid, a New York-based energy marketplace for 
renewable energy, pool local, resident-produced energy. Other people who seek to produce energy as a community could use PEVs to capture, store, and sell back energy to their microgrid. In this way, bidirectional charging could be a potentially integral part of community-led renewable energy generation schemes that seek to "communitize" energy resources for selfsufficient communities consisting of many households.

The timeframe for when these bidirectional charger technologies will penetrate the market and the impact on the cost of PEV charging is currently unclear in the United States. There are no regulations to provide standardization (e.g. for interoperability, EV bidirectional grid-export power, etc. ), interconnection rules, or a clear and viable business case with the exception of the Federal Energy Regulatory Commission (FERC) Order No. 2222 (18 CFR Part 35) described in Section 2.4. EVSE manufacturers need to develop more accessible bidirectional charging technologies for large scale adoption, which requires Underwriters Laboratories (UL) certification for utility acceptance and safety. Currently, there is only one EVSE manufacturer with UL certification, although others are advancing through the process and some have received waivers from the utility to conduct demonstration projects. As we move into the future of bidirectional PEV charging, three key elements need to happen for widespread adoption: (1) on the technology side, automobile manufacturers need to introduce more electric vehicles with batteries that are capable of bidirectionality (allowed tocharge and discharge the battery); (2) industry regulation and the energy economy must adapt to provide standardization as well as technology and market conditions that support business models and viable business cases; and (3) EVSE manufacturers need to develop bidirectional charging technology that is more accessible at scale.

Note, in addition to the Nissan Leaf, Ford recently announced a bidirectional all electric pickup truck, the F-150 Lightning, which they claim could power a home for 3 days.

Volkswagen announced it will enable bidirectional charging on all EVs on its Modular electric drive matrix platform in 2022. Hyundai announced its new Ioniq 5 has bidirectional capability enabled, and Tesla claims it intends to add the capability to future vehicles.

For building the business case, bidirectional chargers need to be made more affordable for consumers through cost reduction, incentives, credits, or a combination of these factors. There are other issues involved in more detailed analysis related to the business case for vehicle to grid interconnection such as metering, regulations, technology comparability, controls for injection into the grid, and compensation for participating PEVs. Behind the meter applications such as demand response and emergency backup for homes (if using a DC charger with an AC converter, islanding, and black-start capability) are currently easier to execute in a number of markets.

The questions are: what is the extent of incentives needed to spur adoption, and who would provide the incentives (federal or state governments, utilities, etc.). In addition, institutional changes such as gaining access to the electricity market or building operations to monetize the electricity and services are required to build a viable business case. For example, leasing models that include bidirectional electric passenger vehicles as well as bidirectional electric mediumand/or heavy-duty trucks, such as buses, refuse trucks, and yard trucks, may attract third-party aggregators to invest in optimization tools to better monetize the bidirectional usage of batteries 
while still accommodating the vehicle users' needs. Maryland's Montgomery County approved a 16-year, \$169 million contract to lease 326 bidirectional electric buses, part of a plan that may replace its 1,422-bus fleet over the next two decades. By leasing the buses rather than buying them outright, the county avoids the upfront cost of electric vehicles; the lease contract costs the same amount as the school system would otherwise spend purchasing, fueling, and maintaining new diesel-powered buses. The Lessor plans to offset the contract cost through operational savings from an electric drivetrain and by monetizing the bidirectional capability of the electric buses.

Some PEV manufacturers have also expressed an interest working with third parties on leasing arrangements that include just the battery to retain monetization opportunities, such as recycling the PEV batteries for stationary power applications ${ }^{1}$. Sections 2.2 to 2.4 both quantitatively and qualitatively identify the factors in the business cases from the perspectives of PEV owners, building owners, and grid operators. Although both PHEVs and BEVs could have vehicle-to-everything (V2X) bidirectional capabilities, the following analysis focuses on bidirectional battery electric vehicles (BDEVs).

\subsection{CONSUMERS' PERSPECTIVE: WHY DO CONSUMERS NEED TO BE INCENTIVIZED?}

\subsubsection{Light-Duty Vehicle Owners}

The total cost of ownership (TCO), either for the vehicle lifetime or per mile, is a metric commonly used to quantify the cost of purchasing and operating the vehicle as an owner or fleet manager. TCO includes vehicle cost and depreciation, financing, fuel costs, insurance costs, maintenance and repair costs, taxes and fees, and other operational costs. Together, they compose a holistic cost of owning and operating multiple different vehicle powertrains.

A recent U.S. Department of Energy (DOE) funded study showed that the total 15-year cost of driving a light-duty BEV could be about $20 \%$ higher than that of a conventional vehicle or hybrid electric vehicle (Burnham et al. 2021). The fuel cost accounts for about 5-7\% of the total cost of driving a BEV, on both a per mile basis and over the lifetime of the vehicle. Figure 2 shows the average cost per mile of driving a small sports utility vehicle (SUV) from model year (MY) 2020, over a period of 15 years. BEV200 and BEV300 stand for BEVs with electric ranges of 200 and 300 miles, respectively. For MY 2020 vehicles, the conventional gasoline-fueled internal combustion engine (ICE) vehicle costs the least. The lower operating cost (especially fuel and maintenance) of a BEV is not sufficient to offset the higher incremental purchase cost. These are average vehicle costs which do not reflect any specific make and model. Note that the TCO shown in Figure 4 does not include the EVSE cost, nor does it include any vehicle purchase incentive or additional value streams that a BEDV could provide.

${ }^{1}$ P3 Conference Hosted Industry Roundtables Bi-directional EVs and Charging Infrastructure January 23, 2020. https://www.energy.gov/sites/prod/files/2020/12/f81/Bidirectional\%20EVs\%20\%20Charging\%20Roundtable\%20 Report.pdf 


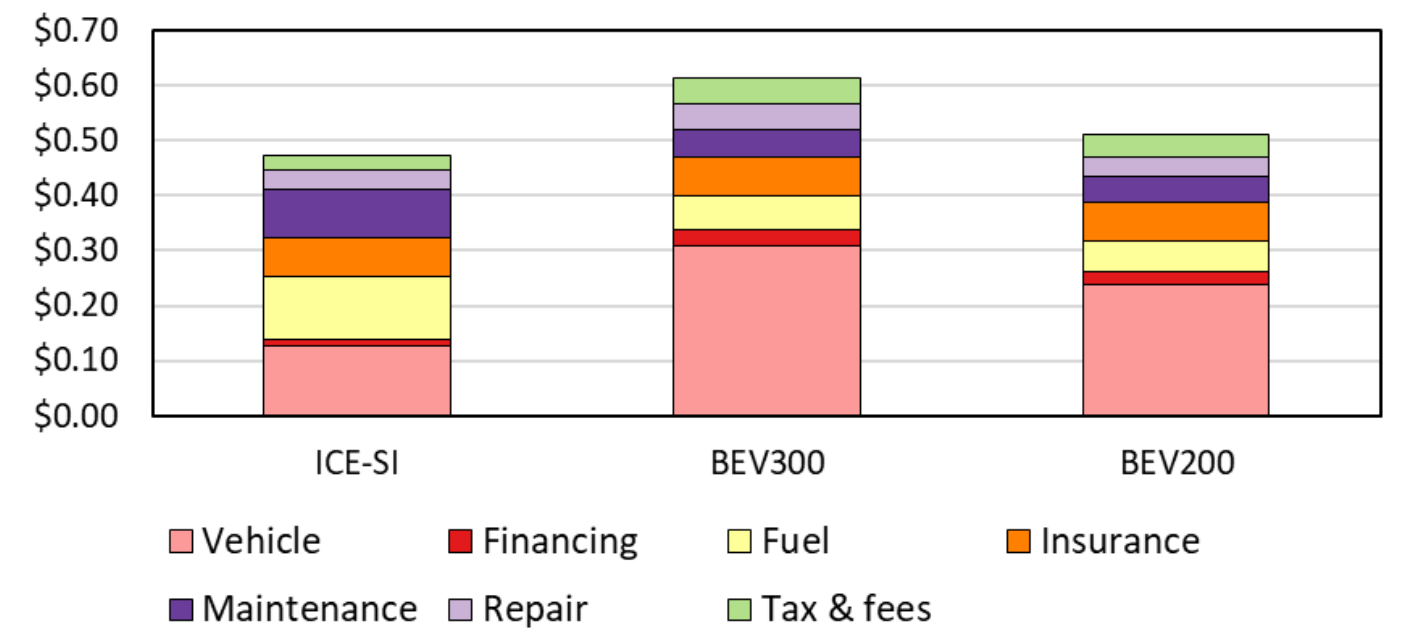

FIGURE 4 15-year per-mile Cost of Driving a MY 2020 Small SUV

Because fuel accounts for only a small portion, 5-7\%, of the levelized cost of driving per mile, bidirectionality will not significantly impact the cost to BEV consumers if it only reduces or eliminates charging costs. Incentives are needed to bring down both the lifetime and per-mile costs of driving in order to encourage the adoption of BDEVs. According to (Burnham et al. 2021), a BEV300 is about $\$ 0.14 /$ mile more expensive than an ICE, while a BEV200 is $\$ 0.04 /$ mile more expensive. In this analysis, we assume that a vehicle is driven 12,000 miles per year. This means that the BEV300 and BEV200 cost \$1,680 and \$480, respectively, more than the ICE per year on average, over 15 years of ownership. If annual incentives can be provided to the vehicle owners above these amounts, then the annualized ownership cost of the BEV300 and BEV200 with bidirectionality would be lower than that of a conventional vehicle. Future research should investigate the incentives needed for different user cases considering various assumptions on annual miles driven, gasoline and electricity prices, and other vehicle operation costs.

In the future, BEV purchase costs are expected to decrease as lower-cost batteries with higher energy densities are commercialized. The average 15-year per-mile cost of driving a MY 2025 BEV300, without the charger expenses, is less than that of the MY 2020 models, as shown in Figure 5. The difference compared to an ICE vehicle is further reduced to $\$ 0.05 / \mathrm{mile}$. 


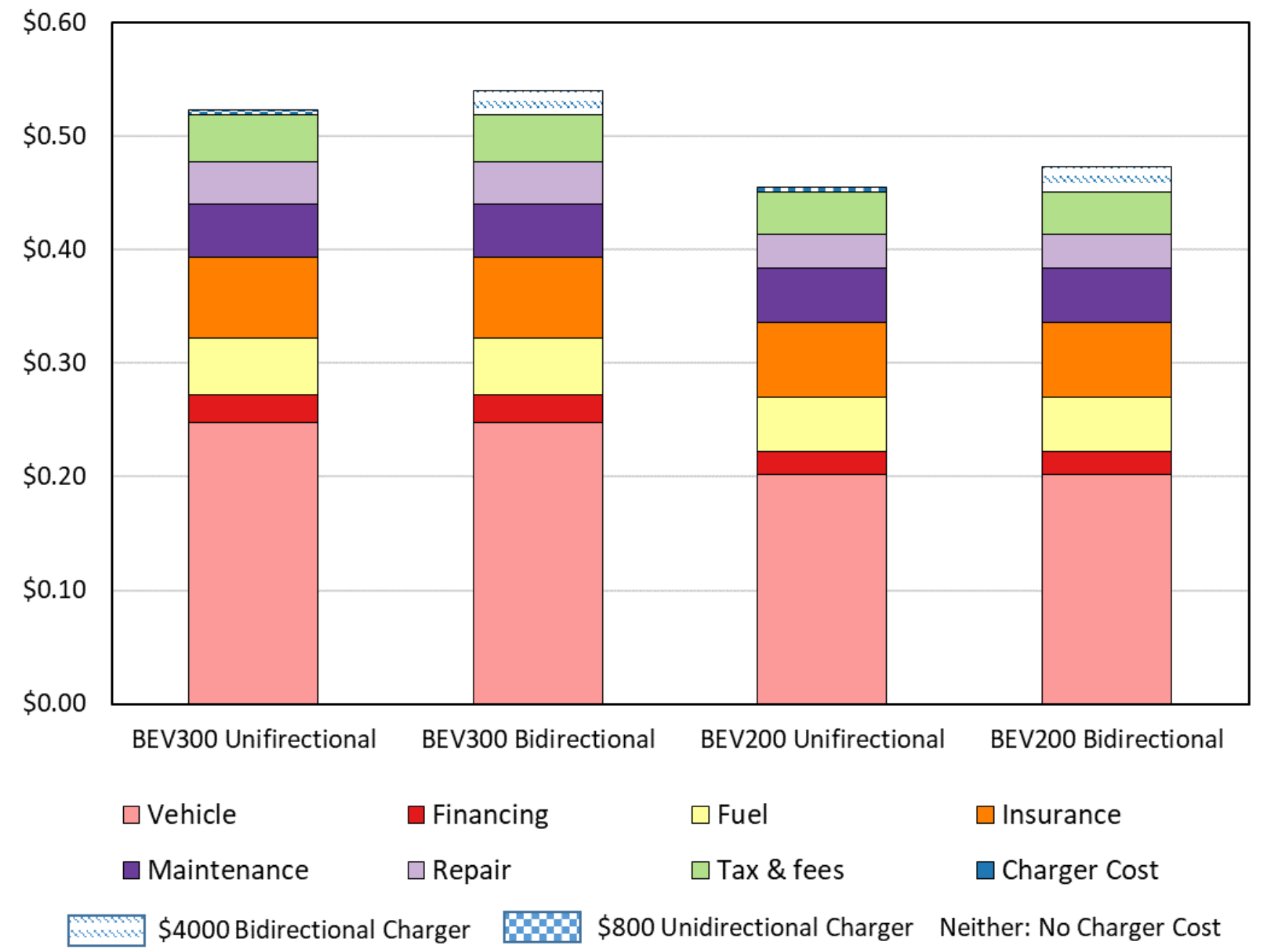

\section{FIGURE 5 15-year per-Mile Cost of Driving a MY 2025 Small SUV, Including Bidirectional or Unidirectional Charger Cost}

The financial benefits of BDEVs will be attractive to consumers compared to conventional vehicles. Many automakers have announced BEV models that will have longer electric ranges, which means they must have a high battery capacity. However, bidirectional chargers would cost more than a conventional one-way charger. A typical level 2 charger for household use is about $\$ 500$ to $\$ 1,000$ per unit, ${ }^{2}$ not counting the installation cost.

Some low-cost bidirectional chargers have received a lot of press. For example, the Wallbox Quasar will have an anticipated selling price of $\$ 4,000$ for a $7.4-\mathrm{kW}$ level-2 charger, ${ }^{3}$ and the Fermata Energy's (2020) anticipated UL9741-certified FE-6 residential charger will have a selling price of about $\$ 4,000$; Fermata's is a $6-\mathrm{kW}$ level-2 charger that provides islanding and

2 Google "Smart EV Charger" and look in the "shopping" section to see typical prices for level-2 smart electric vehicle chargers.

3 See https://electrek.co/2020/01/06/wallbox-quasar-tesla-nissan/. 
black start capability (a complete solution that does not require any existing backup generator) ${ }^{4}$. The installation and wiring costs of a bidirectional charger are expected to be similar to those of a unidirectional charger. As shown in Figure 3, a BEV300 with a bidirectional charger costs only $\$ 0.02 /$ mile more than the one with unidirectional charger, assuming the charger has no residual value at the end of the 15-year lifetime.

Moreover, the typical annual electricity cost $(\$ 1,000$ to $\$ 3,000)$ is about $30 \%$ of an average household's total energy cost (American Gas Association 2019; Davis and Boundy 2020; EIA 2015). An average home uses $29.3 \mathrm{kWh}$ of electricity per day, according to the Residential Energy Consumption Survey (EIA 2015). Therefore, a BEV with a 300-mile range, which requires a battery size of $80 \mathrm{kWh}$ or more, would store enough energy to power a typical family home for about 2 days while still maintaining $25 \%$ of the battery's capacity for travel needs.

Countries in which energy prices vary throughout the day, such as Spain, or where energy companies offer preferential off-peak charging tariffs, such as the United Kingdom, offer PEV owners the opportunity to make money by offering cheaper charging during off-peak hours and selling energy back to the grid during peak hours. Malmgren (2016) estimated that V2G could bring potential income of $\$ 300-\$ 500$ per year to a PEV owner. The lifetime potential revenue is about $\$ 4,000$ on average. Both unidirectional and bidirectional charging, V2X can participate in frequency regulation. Accessibility of PEV owners to frequency regulation markets could potentially offer PEV owners the opportunity to make even more money (Janfeshan et al. 2014; Ferber 2017). For example, Nuuve Corporation tested 30 electric vehicles for the frequency regulation market in Denmark; they estimate that PEV owners there can earn even more, up to $\$ 10,000$ over the lifetime of the car (Malmgren 2016).

\subsubsection{Opportunities for Medium- and Heavy-Duty Vehicles}

Because they have relatively large batteries $(100 \mathrm{kWh}+)$, predictable charging needs, and predictable charging locations, medium-duty vehicles (MDVs) and heavy-duty vehicles (HDVs) (Gross Vehicle Weight Rating 10,000 lb. and above), especially buses, utility trucks, and yard trucks, could be a better choice for certain bidirectional use cases than light-duty vehicles, such as black start and ancillary services. For example, school buses present a good use case because they are centrally planned and operated fleets. They have predictable routes and energy consumption, and have unique availability during the summer when they are not used. Electric buses currently cost approximately $\$ 100,000$ more than diesel-fueled buses, making bidirectionality an important feature to improve the economics given the higher upfront cost.

Illinois' Pekin Public School District has purchased a Blue Bird school bus that uses technology from Nuuve and Rhombus Energy Solutions. It is the first operational DC fast-charge V2G-capable school bus in North America (Mercure 2021). Electric refuse and yard trucks have similar large upfront costs, but often sit idle more consistently than light-duty vehicles throughout the year, making them more available and attractive as bidirectional assets for the grid. Utility trucks may share similar advantages. However, the main purpose of batteries in

\footnotetext{
${ }^{4}$ See https://www.facebook.com/fermataenergy.
} 
BDEVs is to support running the designated routes, and these vehicles are typically operated during the day and sit overnight, which might not be the optimal time to discharge to the grid. If these vehicles have excess battery capacity at the end of their shifts, the energy could be available to support bidirectional charging. These complicated user cases require dynamic decision-making tools to evaluate the tradeoffs and optimize the benefits. Nevertheless, in times of emergencies, such as a grid blackout, typical operations may or may not be the priority and it may be more attractive to use bidirectional vehicles or a subset for emergency purposes which could also be monetized under certain conditions.

Burnham et al. (2021) showed that a class-4 delivery truck with a 150-mile electric range could cost only $\$ 15,000$ more than its conventional counterparts because its technology costs are decreasing over time and conventional vehicle costs are increasing to meet required fuel economy standards. Bidirectionality could potentially create another revenue stream for fleet managers, which could significantly improve their return on investment. Several utilitysupported demonstration projects are currently focusing on MDV and HDV bidirectional charging (SEPA 2019). For example, Exelon is demonstrating and evaluating the barriers to and economics of power from an electric school bus at the Teen Warehouse in Wilmington, and from eight additional BEV sedans in the Delmarva Power \& Light service territory.

\subsubsection{Research and Standard Needs}

Currently, the real cost and lifetime of a bidirectional charger are unknown, as are its depreciation rates. More importantly, future research needs to examine whether the PEV battery would degrade faster due to bidirectionality and therefore cause the PEV value to depreciate faster or lead to premature battery replacement. Battery lifetime is a verycomplex function of charge and discharge profiles and exact battery chemistry and construction. Battery electrochemistries can vary significantly. Using a battery bidirectionally complicates the situation even more. The batteries of different original equipment manufacturers vary in their ability to support bidirectionality. Understanding the best way to charge and discharge a particular battery can require years of testing. Argonne National Laboratory is doing research in artificial intelligence and advanced machine learning to reduce the testing time and improve battery performance (Proffitt 2020). Continued research in this area is necessary to maximize PEV battery lifetimes as charging and discharging patterns become more complex.

R\&D is needed to provide low cost, small bidirectional converters for the PEVs at scale to enable bidirectional operations using AC L2 EVSE in the future. Standards supporting the bidirectional operations are also needed.

\subsection{COMMERCIAL BUILDING OWNERS' PERSPECTIVE: HOW CAN BUILDINGS BENEFIT FROM BDEVS AND SHARE THE BENEFITS WITH BDEV OWNERS?}

Passenger vehicles are typically parked at least $95 \%$ of the time (Schoup 2017). Most of that time, they are parked in garages, driveways, parking lots, or parking structures inside or adjacent to buildings, and thus any chargers for those PEVs are likely to be connected to building 
electrical systems. This makes BDEVs a potential source of behind-the-meter energy storage for those buildings. In particular, vehicles of employees will have long connection/dwell times and known minimum required charge levels (for employees to return home), making them ideal candidates for building-connected BDEVs.

Commercial buildings can benefit enormously from energy storage, with uses ranging from peak shaving and load shifting to provide ancillary services to the grid (Akhil et al. 2013). Figure 6 shows some of the ways in which energy storage can benefit both buildings and the grid. The figure also shows the duration of energy storage throughput. Although some value streams require long-duration storage (meaning a PEV would need to be connected for several hours), a wide variety of value streams would need only short- or medium-duration storage of under one hour. Some value streams are primarily of value to only building owners and some provide value only to the grid; however, some such as power quality and peak shaving provide value to both.

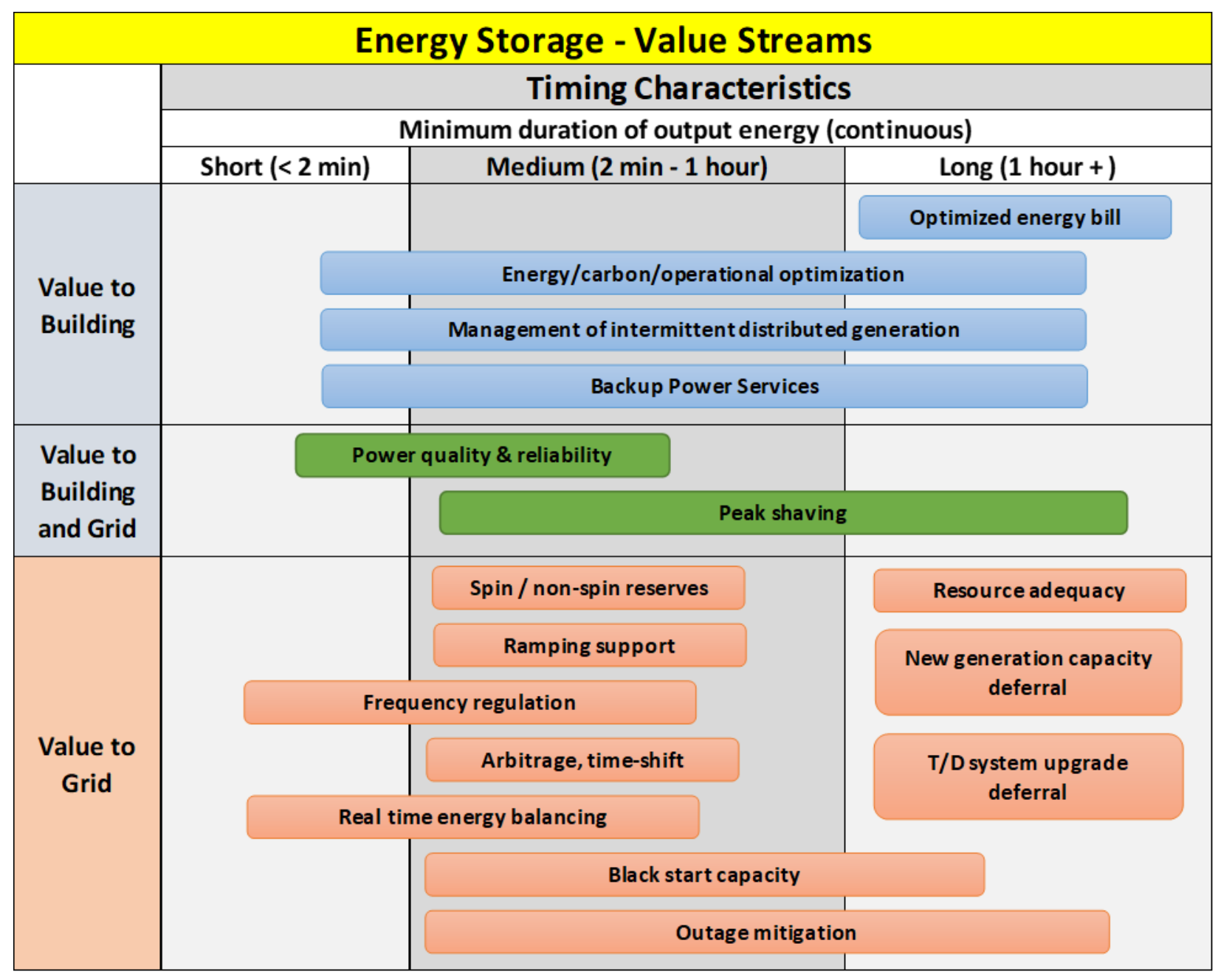

FIGURE 6 Value Streams of Building-Connected Energy Storage to Building Owners and the Grid (adapted from the DOE/EPRI Electricity Storage Handbook, Akhil et al. 2013). 


\subsubsection{Benefits of BDEVs over Stationary Storage inside Buildings}

While the value of energy storage for buildings is clear, safety issues (Blum and Long 2016), space limitations, and cost considerations often preclude the installation of separate battery systems within buildings or on building rooftops, especially in older buildings that are located in densely populated downtown areas of cities. The new Standard for the Installation of Energy Storage Systems, National Fire Protection Association 855 (NFPA 2020) limits the maximum energy storage to $600 \mathrm{kWh}$ in buildings or attached to buildings. This is only as much storage as can be provided by about a dozen BDEVs. The installation of permanent stationary storage also requires additional structural components such as fire walls, fire suppression systems, and additional ventilation systems, which can be costly. BDEVs can provide a much larger total amount of storage without reducing usable parking areas and without requiring additional fire walls, fire suppression, or ventilation systems beyond that required for a standard parking garage.

Large buildings (e.g., high rises, big-box stores) and larger building complexes (e.g., hospitals, shopping malls, industrial facilities) already have the medium-voltage electrical distribution network connections (more than $4 \mathrm{kV}$ and $1 \mathrm{MW}$ ) that would be needed to connect dozens of BDEVs to the grid. Therefore, the main capital costs for connecting many BDEVs to such buildings is primarily for chargers and electrical safety protective devices, not large-scale electrical infrastructure upgrades, especially if the building electrical service is already sized to handle the potential load for any type of EV charging. BDEVs thus provide an opportunity for many building owners to add electrical storage to their building at a reduced cost (primarily only the cost of a bidirectional charger and wiring), with reduced safety issues, and without requiring any physical space beyond that already provided for employee and visitor parking.

\subsubsection{Peak Shaving and Demand Charge Reduction}

In medium to large commercial buildings, utility tariffs (electricity bill rate structure) typically include a demand charge: a charge on the utility bill related to the peak power draw that accounts for the infrastructure needed to supply the demand (cables/transformers) and to ensure that enough power generation is available to deliver power at the time of peak demand. It is not uncommon for demand charges to represent up to $70 \%$ of the monthly utility bill (Dieziger 2000). Facilities with highly variable loads (including industrial and test facilities, laboratories, stadiums and arenas, and buildings with a mix of retail, office, and residential space) are particularly susceptible to high demand charges. Building-connected BDEVs can be used to temporarily store electricity to provide enormous peak shaving of the composite load, as shown in Figure 7. Doing so provides direct and immediate economic benefits to the building owner at a fraction of the capital costs required to install permanent stationary storage. 


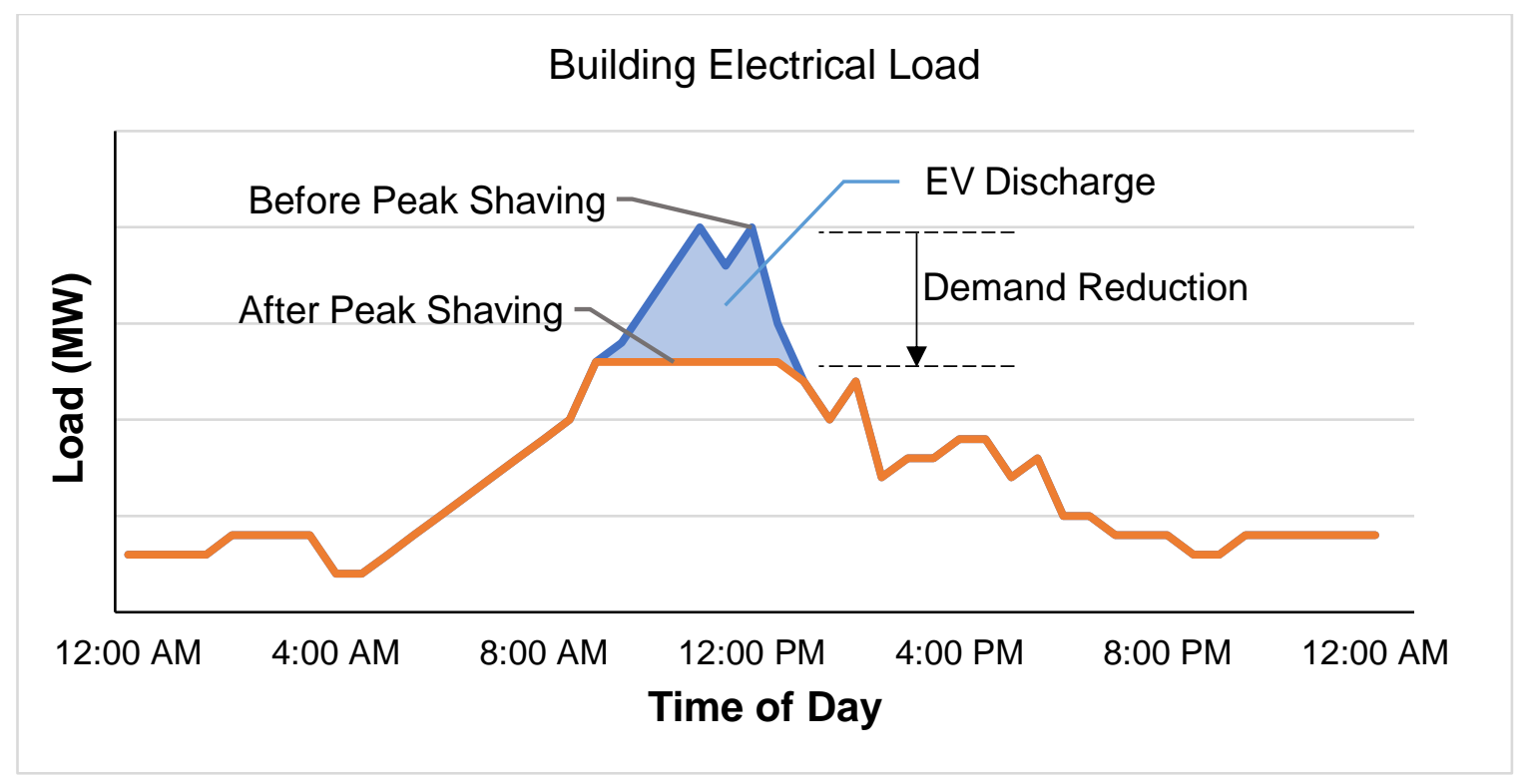

\section{FIGURE 7 Use of BEVs to Provide Peak Shaving and Demand Control to a Building}

Figure 8 shows a map of maximum demand charges in each utility service territory and Table 1 shows that the states with the highest maximum demand charges (McLaren et al. 2017) also tend to be the most urbanized states where PEV ownership is currently concentrated. Many of the tariffs with high demand charges have lower energy charges. Across the United States, millions of customers could reduce their utility bills by moving to the higher demand charge tariff if they also had an affordable way to provide peak shaving. Using BDEVs as semistationary energy storage can make that possible. Because the cost to the utility to provide the required peak demand has dropped, the utilities should not lose money in the exchange. This could also benefit ratepayers more generally. 


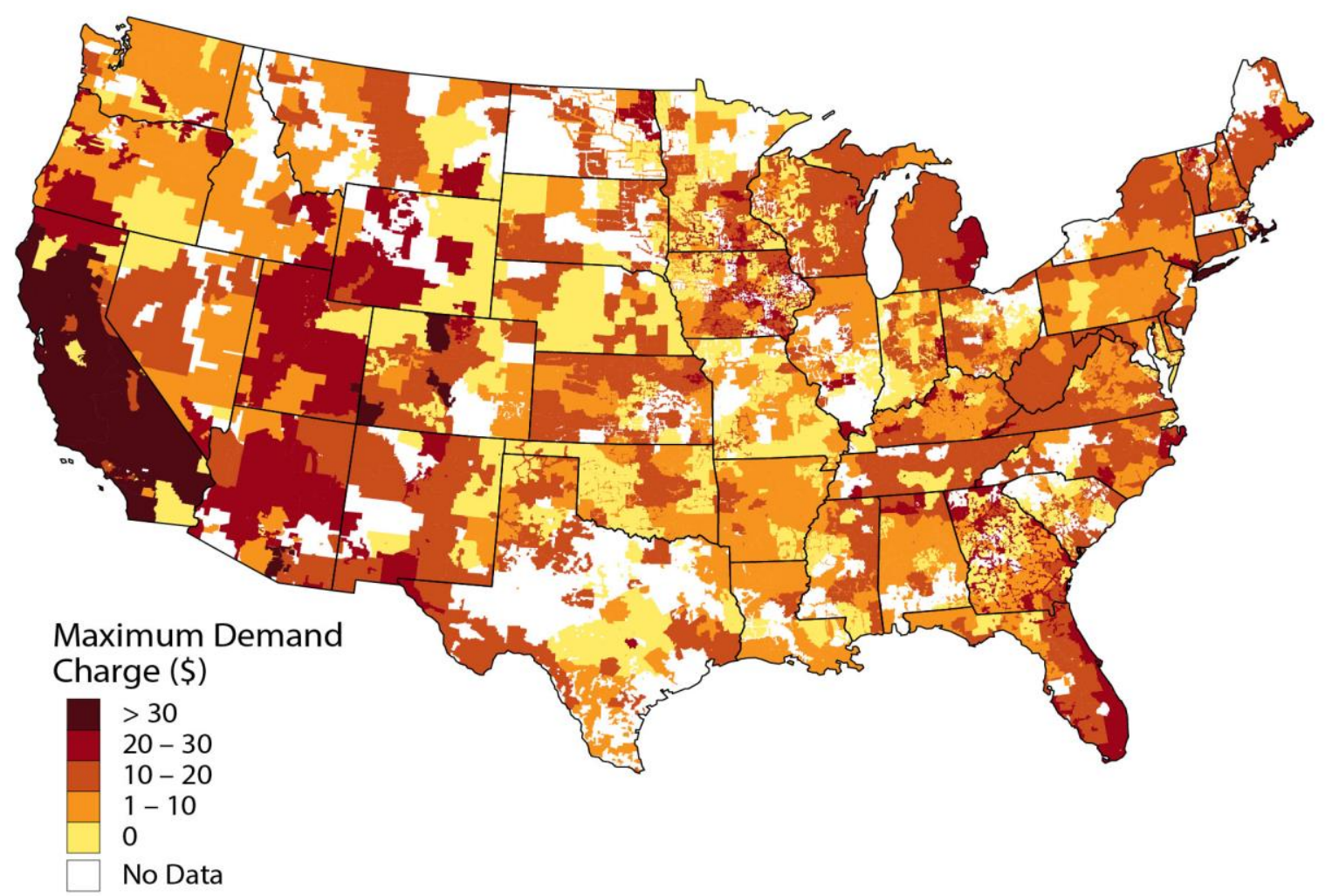

FIGURE 8 Maximum Demand Charges across the United States (taken from NREL 2020; McLaren et al. 2017).

In a recent demonstration, Fermata Energy showed that a single BDEV discharging at $12.5 \mathrm{~kW}$ for only 15 minutes a month to reduce the peak load was able to reduce demand charges by nearly $\$ 800$ over the 5-month test period in a location where the demand charges were just over $\$ 15 / \mathrm{kW}$ (Fermata Energy 2020). Extrapolated to a high-demand region of New York, such use would save over $\$ 7,500$ per year, suggesting an investment payback time of under 2 years.

\subsubsection{BDEVs as Battery Backup to Buildings}

Another benefit for commercial building owners is the use of BDEVs for backup storage in the case of outages during the main part of the workday. The capital cost to install permanent stationary storage often cannot be justified simply for use as a backup power source, because of the difficulties in valuing a backup system. In general, quantifying resilience continues to be a challenge in the energy industry. However, with a reduced capital cost compared to stationary storage, using BDEVs as backup storage can be much easier to justify. Table 2 compares typical costs to
TABLE 2 States with the 10 Highest Demand Charges.

\begin{tabular}{lc}
\hline \multicolumn{1}{c}{ State } & $\begin{array}{c}\text { Maximum } \\
\text { Demand Charge }\end{array}$ \\
\hline New York & $\$ 51.25 / \mathrm{kW}$ \\
California & $\$ 47.08 / \mathrm{kW}$ \\
Colorado & $\$ 46.23 / \mathrm{kW}$ \\
Massachusetts & $\$ 41.25 / \mathrm{kW}$ \\
Arizona & $\$ 35.45 / \mathrm{kW}$ \\
Nebraska & $\$ 30.00 / \mathrm{kW}$ \\
Illinois & $\$ 30.00 / \mathrm{kW}$ \\
Georgia & $\$ 28.70 / \mathrm{kW}$ \\
\hline
\end{tabular}


provide $3 \mathrm{MWh}$ of storage for a building with a permanent battery system and to provide the same amount with BDEVs assuming the typical BDEV capital cost will be less than one-half that of a permanent energy storage system.

TABLE 3 Capital Costs for a Building Owner to Install 3 MWh of Storage

\begin{tabular}{cccc}
\multicolumn{1}{c}{ Type } & Cost per Item & Total Energy Storage & Total Cost \\
\hline $\begin{array}{l}\text { Stand-Alone Battery } \\
\text { BDEVs }\end{array}$ & $\$ 800$ per kWh $^{\mathrm{a}}$ & $3 \mathrm{MWh}$ & $\$ 2.4$ million \\
\hline
\end{tabular}

a Typical fully installed cost in 2020 for building installed storage in the $1-5 \mathrm{MWh}$ range.

b Typical installed cost for a stage-2 BDEV charger when multiple chargers are installed at the same time. A two-unit, level-2, bidirectional pedestal charger costs about $\$ 15,000$ and. There is a $\$ 5,000$ installation charge per unit for 40 units.

c Only $60 \mathrm{BDEV}$ s need to be connected to provide $3 \mathrm{MWh}$ of storage, but an owner would likely install more chargers than is strictly needed to provide the desired amount of BDEV storage.

As an example, the Johan Cruijff Arena (JCA) in Amsterdam, home to the Ajax soccer team, is installing 20 two-car bidirectional EV chargers in VIP and skybox parking decks as part of a pilot (Warmerdam et al. 2020). The facility plans to offer either direct payments or reduced parking rates to EV owners who allow use of their vehicle battery for peak shaving and provide backup power. With a $10-\mathrm{kW}$ peak discharge available from each BDEV, $50 \mathrm{BDEV}$ s could potentially provide JCA with $400 \mathrm{~kW}$ for peak shaving, which represents $12 \%$ of its peak load. If an average of $40 \mathrm{kWh}$ of energy is available from each BDEV, $50 \mathrm{BDEVs}$ can provide 2,000 $\mathrm{kWh}$ of storage. This amount of storage is enough to provide 1 hour of operation during a regular soccer match; thus, only $200 \mathrm{BDEVs}$ would be required to provide the necessary backup power for an entire 4-hour match. JCA is investigating potential business models for this; options could include direct payments to BDEV owners or reduced parking rates and streamlined facility access in exchange for making the BDEV available for use by JCA.

For building owners who are also employers, PEV charging can be used as an employee benefit (discounted parking, free or low-cost charging). Thus, the infrastructure costs might be considered, at least in part, a fringe benefit that could change the accounting and cost structure in a way that makes such facility upgrades more affordable.

\subsubsection{Buildings as Transactive Hubs}

At the same time that BDEVs can provide benefits to the building owners, a larger building acting as an energy hub could provide added benefits to BDEV owners. A building energy hub that is behind the meter could allow peer-to-peer transactions. A BDEV with extra charge, trading with a PEV owner needing charge, could pass directly through the building electrical system and completely bypass the electric grid. This type of peer-to-peer transaction can benefit PEV owners without requiring the inconvenience, regulation, and safety or security implications of selling power back to the grid. While the development of low-cost revenue grade metering makes this technically possible, such transactions are currently precluded in many 
locations because of state regulations related to electricity sale and regulatory changes would be necessary to make these transactions a viable business opportunity.

Large buildings and building complexes provide a natural marketplace for an enormous variety of services to be transacted (space, staff, equipment, etc.) that can help support the financial infrastructure necessary for a transactive energy system. For example, the building owner might implement a micro-transaction system that uses phone apps and a centralized database to provide validated, auditable accounting that is finalized and cleared periodically. The sheer volume of transactions possible in a large building makes such micropayments a viable business model that might not be practical for stand-alone BDEV charging. Blockchain or similar systems would need to be developed to facilitate such peer-to-peer transactions.

Furthermore, BDEVs provide building owners another set of aggregated energy resources that they can monetize to provide energy and services directly to the grid or to a microgrid. As part of a microgrid, the building can serve as the aggregator of BDEVs connected to the building using additional controls and software that make integration easier. A series of buildings with connected BDEVs could also be aggregated using additional tools provided by an aggregator or by a utility using a distribution management system (DMS) and/or a distributed energy resource management system (DERMS) to manage integration to the grid.

\subsubsection{Research and Standard Needs}

One of the biggest limitations to buildings acting as transactional energy hubs are state regulations that limit the sale of electricity. Continuing research is needed to analyze different potential regulatory structures and electricity market constructions, especially in peer-to-peer markets, to inform policy makers. In addition, while standards are being developed related to control of grid-connected devices and for the general transaction of energy, standards specific to the use of BDEVs as semi-stationary storage for buildings will need to be developed in order to ensure that differing manufacturers of BDEVs, BDEV chargers, and building energy hub electronics are fully interoperable. And, while low-cost revenue-grade metering and controls are under development, additional research is required to continue to reduce equipment costs and help bring the technologies to market.

\subsection{UTILITY PERSPECTIVE: WHERE AND HOW TO INCENTIVIZE}

\subsubsection{Mobility Revolution Has Significant Impacts on the Grid}

Utilities and large renewable energy owners can benefit from traditional EVs with one way power flow from the grid to EVs through smart charging management. The two-way power flow (bidirectionality) would bring additional flexibility and more benefit if work along with smart charging management. Specifically, a BDEV can discharge electricity back to the grid, especially when renewable generation is low, in addition to its normal charging capability as a load on the power grid. Bidirectionality will enable many additional capabilities and create new benefit streams. The immediate interaction is with the electricity distribution network. A distribution system operator (DSO) may leverage BDEVs to control voltage, reduce load loss, 
and defer system upgrades. As adoption rates increase, the impact of BDEVs would expand from the distribution grid to the transmission grid, and the corresponding wholesale electricity markets. Additional system integration tools/software would be required to aggregate and optimize integration. This could include tools such as DMS and DERMS to communicate with the transmission system operator. The impact would range from short-term grid operation to long-term generation and transmission capacity expansion, to ensure adequate capacity to accommodate large-scale adoption in the future. For example, a PEV can be charged (i.e., buy electricity) when electricity prices are lower and can be discharged (i.e., sell electricity) when prices are higher. In this way, an owner can make revenue or offset total charging costs by arbitraging the prices.

From the grid perspective, this may mitigate generation shortages or grid congestion that causes higher electricity prices if optimal locations are chosen. Technically, a BDEV can also provide essential reliability services to the grid by injecting active and/or reactive power and providing frequency regulation, spinning/non-spinning reserve, ramping, voltage support, and black start capabilities, to improve grid reliability and resilience. For example, if aggregated using software tools, BDEVs can quickly ramp up (or down) its charging (or discharging) speed when the grid requires regulation services. Another example is that a utility or aggregator may be willing to aggregate BDEVs connected to bidirectional chargers via residences to provide the grid with energy or energy services and in some cases act as virtual microgrids. Some of the grid services are products (e.g., regulation up or down, spinning reserve) in an electricity market, where a BDEV owner can receive revenue by providing these services. Some are not products (e.g., black start capability) in a market, but a BDEV owner can still receive cost-based compensation.

In practice, BDEVs usually interact with the grid through aggregators or utilities using DMS and/or DERMS, who manage charging of a group of vehicle owners so that the grid service can be provided technically and profitably on behalf of the owners. For example, an individual BDEV owner may not be qualified to participate in a wholesale market for service provision, but they may be able to participate, along with other BDEVs owners, as a member of an aggregate group. In this situation, an aggregator may estimate the grid's capacity to provide service for a given time from their managed fleet and bid this capacity into a wholesale electricity market. If the bid wins, the aggregator would coordinate the charging activities among BDEV owners to provide the services.

On the regulatory side, FERC issued the landmark Order No. 2222 in 2020 (FERC 2020) to facilitate distributed energy resources (DERs) participating in the wholesale electricity markets. It particularly applies to resources with small-scale capacity (typically $1-10,000 \mathrm{~kW}$ ) that can provide an alternative to or an enhancement of the traditional electric power system. The order paves the road for BDEVs to provide energy and grid services to the wholesale market. For example, PEV owners could opt into aggregation programs with utilities or third parties to provide energy or grid services. Regional grid operators are currently working to revise tariffs to establish DERs as a category of market participant, and each tariff must set a size requirement for resource aggregations that does not exceed $100 \mathrm{~kW}$. 
Table 3 summarizes the potential use cases for BDEVs in the power grid, categorized into transmission system, distribution system, and end customers. According to a recent V2G projects review (Edwards and Landi 2018), most use cases are in the distribution system (e.g., time shift charging and DSO services), likely due to the small size of the projects and the application context. Frequency Response provision is the most tested use-case in the transmission system domain. As regulatory support (e.g., FERC Order No. 2222), state policies, and penetration increase and mechanisms for cost recovery mature, user cases in the transmission system and in wholesale markets will increase and become dominant.

TABLE 4 BDEV Use Cases

\begin{tabular}{|c|c|c|c|c|}
\hline \multicolumn{3}{|c|}{ Transmission System (Wholesale market) } & $\begin{array}{l}\text { Distribution } \\
\text { System }\end{array}$ & Customer \\
\hline $\begin{array}{c}\text { Bulk } \\
\text { Energy }\end{array}$ & Ancillary Services & $\begin{array}{c}\text { Transmission } \\
\text { Services }\end{array}$ & $\begin{array}{c}\text { Distribution } \\
\text { Services }\end{array}$ & $\begin{array}{c}\text { Energy } \\
\text { Management }\end{array}$ \\
\hline Capacity & Regulation & $\begin{array}{c}\text { Congestion } \\
\text { Management }\end{array}$ & $\begin{array}{c}\text { Congestion } \\
\text { Management }\end{array}$ & Time Shifting Charging \\
\hline $\begin{array}{c}\text { Energy } \\
\text { Arbitrage }\end{array}$ & $\begin{array}{l}\text { Spin/Non-Spin } \\
\text { Reserve }\end{array}$ & Upgrade Deferral & Upgrade Deferral & $\begin{array}{c}\text { Demand Charging } \\
\text { Reduction }\end{array}$ \\
\hline & Voltage Support & & Voltage Control & Backup Power \\
\hline & Black Start & & Loss Reduction & $\begin{array}{l}\text { Increased PV Self- } \\
\text { Consumption }\end{array}$ \\
\hline & $\begin{array}{l}\text { Frequency } \\
\text { Response }\end{array}$ & & & \\
\hline
\end{tabular}

In addition, renewable energy could be better used by aggregating and leveraging BDEVs. For example, the highly variable nature of wind generation causes significant energy imbalances in the power system. BDEVs have the potential to mitigate these imbalances through both charging and discharging strategies. One study evaluated the potential of BEVs to meet the entire additional energy imbalance imposed by adding $10 \mathrm{GW}$ of additional wind power to the North West Power Pool. The results indicate that BDEVs could make a substantial contribution toward meeting the new balancing requirements associated with the growing grid integration of wind technology. As discussed above in this section, through the use of technologies and regulatory support, BDEV owners can provide significant flexibility and dispatchability to balance energy generation and consumption for homes, buildings, and the grid. This is a great resource that can mitigate the curtailment of renewable generation caused by its uncertainty and variability.

\subsubsection{Impact on Transmission and Distribution Grid}

Large-scale adoption of PEVs will not only increase overall electricity consumption but may also increase peak demand. The flexibility of BDEVs, however, can help reduce or shift peak load through demand response. However, to retain this benefit as adoption rates increase, grid capacity must be upgraded to relieve overall pressure on peak and total energy consumption. 
A recent study shows that the adoption of $\mathrm{V} 2 \mathrm{G}$ technologies will reduce grid operational costs. However, costs will increase along with the penetration rate if the grid is not upgraded, as illustrated by Figure 9. (Guo et al. 2019). In the future, BDEV-related technologies will advance and transportation modes will evolve, significantly influencing the evolution and distribution of regional charging demand in time and space. For example, ride-sharing models will save more energy compared to individual ownership models.

High degrees of automation generally result in higher fuel consumption. Therefore, if a region adopts mainly BDEVs with high automation for individual ownership, we may see even greater increases in electric charging demands. In addition, if regional adoption rates are not uniform, demand evolution will be more complex. The demand profile (peak and total) can be managed by smart charging strategies to reduce cost, mitigate grid congestion, and defer grid upgrading from the short term to the long term. With more automation, there may also be more optimization opportunities for owners that warrants additional analysis to better understand the dynamics and outcomes.

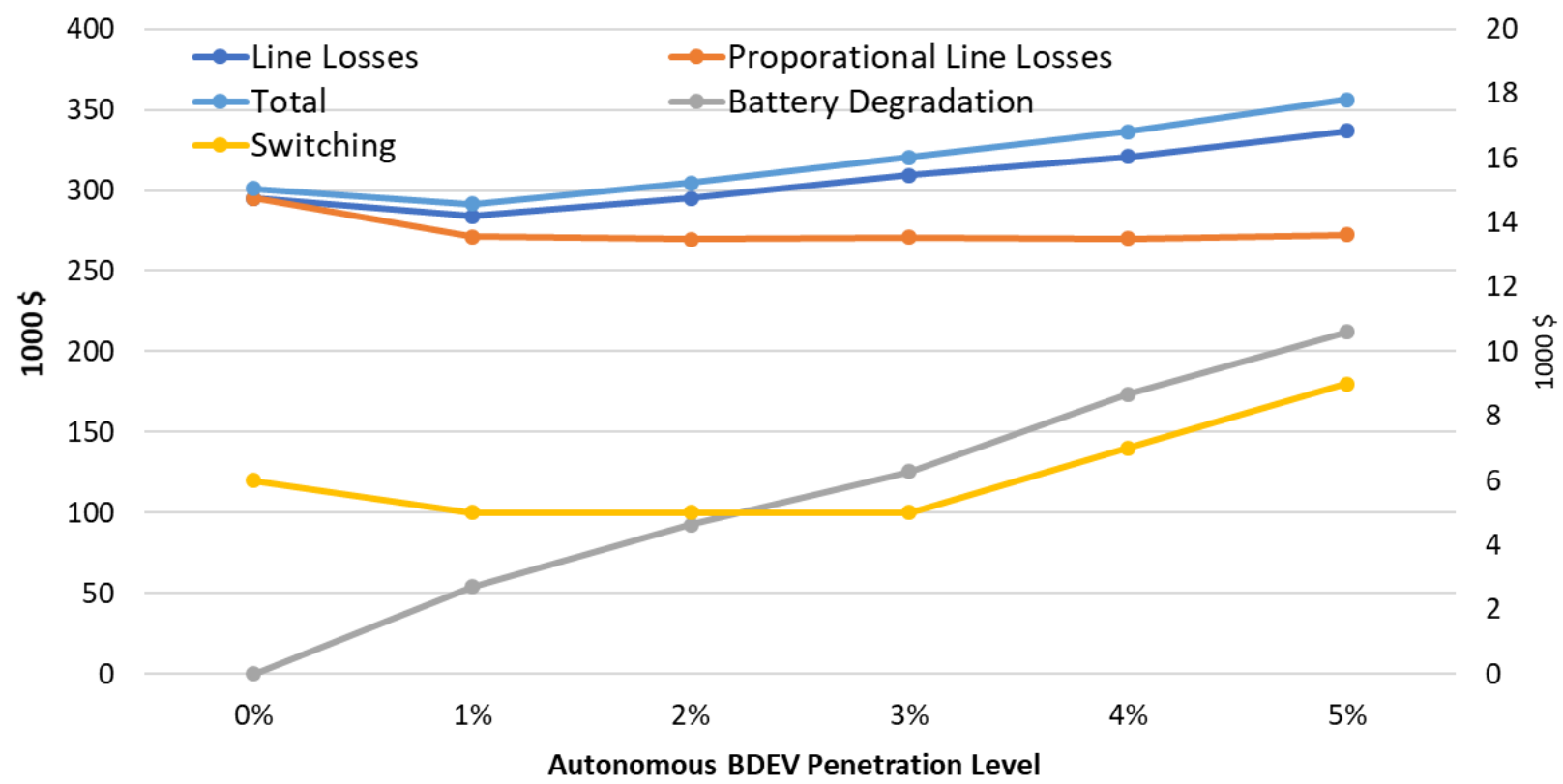

FIGURE 9 Cost Impacts on Grid with BDEV Penetration (updated from Guo et al. 2019).

The evolution of PEV charging demand and the capability to provide grid services will have large impacts on scheduling and dispatching generation assets in the transmission grid. A power grid operator keeps the generation and load balanced by dispatching the cheapest available generation units in order of economic merit. At each time step, the marginal cost of the last dispatched unit determines the system marginal cost at that time step, which dictates the wholesale price in a market-based system. This varies by size of the unit, location, jurisdiction and other factors. If charging demand from BDEVs affects the total system demand profile and changes the dispatch order and marginal units, it will also change the total system operational cost, marginal cost, and marginal prices. In the short term, this will change the revenues of generation units. Over the long term, it will accelerate the retirement of existing generation units 
that provide peak power capacity whose profitability is less competitive, and investment in new generation technologies.

The batteries in BDEVs offer a promising alternative to provide grid services, which are usually provided by conventional fast ramping generation units. BDEVs could cause changes in the generation mix throughout all timeframes. Similarly, this will result in changes in the power flow of the grid, and eventually require upgrades to transmission lines and the grid network topology. However, it is important to evaluate whether the cost of upgrading infrastructure to integrate BDEVs would be less than the estimated costs to upgrade infrastructure to accommodate unidirectional EV charging. For example, in some cases, software and controllers, which are often cheaper than traditional grid infrastructure used to increase supply, may be an adequate solution to resolving electricity supply issues caused by EVs by aggregating and leveraging BDEVs and their charging infrastructure connected on the distribution system to serve as virtual microgrids. In addition, BDEVs could offset stationary storage that utilities would have had to add otherwise. The Brattle Group published a report that estimates \$75-125 billion of investment is needed across the electric power sector to serve 20 million unidirectional EVs by $2030 .^{5}$

On the distribution grid side, large-scale adoption of bidirectional PEVs will impact charging network deployment, hosting capacity expansion, and grid operation constraints, such as congestion mitigation and voltage control. Aggregated charging demand that simultaneously charges at a single distribution node could cause reliability issues. It may become a greater challenge with higher voltage DC fast charging (DCFC). The planning and expansion of a system-wide charging network should account for the operating limits of the distribution system and the expansion of hosting capacity. Inappropriate planning of a charging network could hurt the distribution network operations (e.g. its voltage profile and waste hosting capacity). Meanwhile, it is critical to coordinate between the distribution grid and traffic system planning and control to avoid traffic congestion or grid operation violation. In addition, managed BDEVs can be coordinated with other distributed resources and distribution network topology control techniques to improve distributed energy utilization and grid reliability (Guo et al. 2019). For example, managed BDEVs could help offset intermittency from renewable energy sources or absorb renewable energy that would have otherwise been curtailed.

The major costs of BDEVs come from batteries and from battery degradation, which is partially a result of customer charging behavior. More irregular charging and discharging may accelerate degradation but could be offset based on new revenue streams as discussed earlier. Longer dwell times or less favorable charging locations may reduce the preference (or comfort) for a customer's car to charge. These opportunity costs must be balanced with the benefits discussed above and compensated through viable business models.

\subsubsection{Research and Standard Needs}

\footnotetext{
5 See https://www.brattle.com/news-and-knowledge/publications/getting-to-20-million-evs-by-2030-opportunitiesfor-the-electricity-industry-in-preparing-for-an-ev-future.
} 
To facilitate large-scale adoption of BDEVs and to maximize the potential benefits for stakeholders, it is critical to develop tools that can help PEV owners and fleet operators manage the charging and grid service provisions in home/building energy management and wholesale electricity markets. Similarly, it is important to develop tools for DCFC stations and help station operators identify opportunities where they can serve as assets to the grid and ensure long-term economic viability. Potential host sites for bidirectional EV charging equipment would also benefit from tools that identify value streams.

Another unique research challenge is to model uncertainty of BDEVs access points to the grid. Different from traditional DERs, BDEVs could access the grid at different locations depending on travel demand patterns. It creates opportunities of flexibility in both space and time dimensions, but also challenges to model more complex uncertainty comes with mobility. Although some uncertainty can be mitigated with bidirectional EVs that utilize off-board bidirectional chargers which would be stationary. The uncertainty could be more random at the individual BDEV level due to characteristics of travel and battery capacity, but more predictable on an aggregate level over time and space dimensions. Therefore, it would be critical to forecast the dynamics of net storage capability at multiple scales with appropriate representations, from the feeder level, to across a utility territory, or even for an entire transmission network system. Incorporating these more accurate representations of BDEVs into grid planning and operational models would better capture the benefits of BDEVs.

On the grid and infrastructure side, it is important to develop representations of BDEVs and charging stations with an appropriate level of detail to model physical and cost parameters and operational constraints. These models should be integrated into existing grid operations and planning tools, in order to take advantage of BDEVs as resources of both demand and grid services to support grid reliability and resilience in both short- and long-term scenarios. In addition, systematic technoeconomic analysis would help stakeholders to understand the impact BDEVs have on the grid over multiple time and space scales, with multiple infrastructure configurations, as well as their costs and benefits compared to other technologies (e.g., conventional EVs with controlled charging). 


\section{CHALLENGES AND OPPORTUNITIES}

There are unique challenges and opportunities inherent in deploying BDEVs. PEVs today are only capable of providing V2X when connected to DC chargers and that RD\&D is needed on an onboard bidirectional converter that would allow BDEVs to perform bidirectional charging when connected to AC Level 2 chargers, which account for the vast majority of EVSE deployed today. Future vehicle, charger and battery technologies will need to reduce the cost and prevent battery degradation due to bidirectional charging. Other issues such as communications and control standards would also have to be addressed.

Deploying BDEVs mainly involves BDEV batteries and chargers, as well as the software to forecast, optimize, and transact monetization opportunities. In addition, hardware is needed to enable the grid to handle V2X. Education and outreach are also imperative to educate consumers, building mangers, utilities, and other stakeholders about the technology available and the potential cost and benefits.

Artificial intelligence and machine learning can be used to simulate battery degradation and inform manufacturers and insurance companies as they develop appropriate warranty coverage terms for BDEV batteries. This could also inform automakers, battery manufactures, third-party aggregators, and other finance entities that would like to explore innovative business models such as leasing schemes that allow the aggregator to monetize the BEDV battery, similar to the arrangement Montgomery County entered into, as described in Section 2.1.

These leasing schemes could involve a third party retaining ownership of the entire $\mathrm{BDEV}$, or just the bidirectional battery, and leasing to the vehicle end-user. These leasing schemes become particularly interesting not just from a V2X standpoint, but also from the endof-life standpoint, because these batteries can be recycled and reused. Battery recycling and reuse is an interesting opportunity for BDEV owners. PEV batteries are typically replaced after the battery usable capacity has degraded to $80 \%$. However, these batteries are well suited for standalone applications (Curtis et al. 2021; Kelly and Winjobi 2020).Moreover, cost-benefit analysis could be conducted to access whether reclaiming critical materials from used packs is more beneficial and profitable than trying to analyze, diagnose, and recondition used packs for stationary storage applications.

Traditional DCFC stations, ${ }^{6}$ which are being targeted along highway corridor systems, could add significant strain to the grid and introduce the need for new expensive upgrades. Meanwhile, utility operators and owners have been slow to make grid modernization investments and may even be reluctant to approve or delay traditional DCFC station even though they are eager for load growth. The current business model often deployed further exacerbates the delay in deploying DCFCs. The traditional DCFC's primary revenue stream is charging payments from PEV drivers who wish to charge vehicles. However, DCFC stations could also become microgrids that provide more value to the grid and could be monetized by DCFC station owners.

\footnotetext{
6 Traditional DCFC sites are not co-located with storage, renewables, or microgrids. Note that advanced microgrids could be co-located with DCFC sites and would include storage, renewables, and a controller to provide islanding capabilities.
} 
Note that DCFC and microgrids share many of the same upfront costs and components which creates a unique opportunity, particularly if storage and renewables were already being considered as part of the DCFC station. Therefore, under the right conditions, the additional marginal cost of adding a controller to provide islanding and optimization for a microgrid could be offset by the monetization opportunities that the microgrid could offer to the DCFC station. This could help provide owners of DCFC stations much-needed revenue streams; existing business models have not been viable in many locations, thus hindering deployment and proper maintenance.

In addition, combining DCFC stations with microgrids could also help ensure utility and grid operator acceptance and interconnection due to the high charging power. The microgrid layer could not only help alleviate negative impacts to the grid but also provide valuable services to the grid such as those listed in Figure 6. These services could help the utility offset more expensive grid infrastructure upgrades that would otherwise be needed to serve the DCFC station charging demand. DCFC co-located with microgrids and grid digitization could also help better integrate intermittent renewable generation in the system. These benefits can be further amplified by aggregating combined DCFCs and/or microgrids within a region or transmission system. In summary, co-locating DCFCs and microgrids may not only resolve reliability concerns but also elevate them into resilience assets that utilities can harness at potentially lower cost.

Global energy markets are transitioning to more decentralized, distributed resources and transactions. A possible vision for the future of the nation's energy grid involves homeowners selling unused power stored in stationary or vehicle batteries during times of need to others in their communities (Andoni et al. 2019). The current structure of energy and electricity markets is inadequate to allow small players to participate in the markets, and incentives for active consumer participation are insufficient. Regulatory changes similar to the ones mentioned in the previous section may also be needed to realize this vision.

Blockchain technology is an emerging solution to this opportunity that could provide new forms of consumer participation in transactive markets (NREL 2020). Blockchain serves as a distributed digital record of actions agreed upon and performed by multiple parties. Blockchains promise transparent, tamper-proof, and secure systems that can enable novel business solutions, especially when combined with smart contracts. Early blockchain developers are establishing transactional digital platforms that can be decentralized, enabling person-to-person energy trading (Singh 2021). AI and machine learning will also be useful in managing and balancing the increase in two-way flow activity on the grid. 


\section{CONCLUSIONS}

This report identifies the key issues that factor into the business cases of key stakeholders including the PEV owners, building owners, and grid operators. This preliminary analysis helps to define the key factors in making the business case for bidirectional use of PEVs and charging infrastructure and charting the path forward for more rapid adoption.

For light-duty PEV owners, because fuel only accounts for a small portion, 5-7\%, of the levelized cost of driving per mile, bidirectionality will not significantly impact ownership costs if it only reduces or eliminates the fuel costs. Incentives or additional profits from selling the electricity back to the building or the grid are needed to bring down both the lifetime and the permile cost of driving in order to encourage the adoption of BEVs with bidirectionality.

However, the availability of bidirectional chargers is currently limited, so their real commercialized costs and depreciation rates are unknown. More importantly, future research needs to examine whether the PEV battery would degrade faster due to bidirectionality and therefore possibly depreciate the PEV value faster. Battery lifetime is an extremely complex function of charge and discharge profiles and exact battery chemistry and construction. However, PEV batteries could be a great source of backup generation for home owners, which is difficult to quantify.

Because their batteries are relatively large, and their charging needs and locations are predictable, MDVs and HDVs - especially school buses (in the summer) and utility truckspresent a unique opportunity for bidirectional business cases. Bidirectionality could potentially create another revenue stream for fleet managers, which could significantly improve their return on investment in electrification.

For residential building owners, the primary benefit of a BDEV is to provide backup power. For commercial building owners, especially large building owners, BDEVs can provide an affordable alternative to the installation of stationary storage to provide peak shaving to reduce demand charges and to provide backup power. Commercial building owners can share those savings with BDEV owners to help incentivize BDEV owners to connect to the building and allow bidirectional energy flow. However, regulatory changes and lower cost metering and controls technology are needed to allow building owners to buy and sell electricity to BDEV owners and to allow them to manage peer-to-peer energy transactions between BDEV owners.

As a resource to the power grid, BDEVs may not only reshape the load profiles, but also provide grid services in a mobile way. The flexibility BDEVs offer will benefit the grid (microgrid, distribution grid, and transmission grid) on many fronts, including energy and reliability services to ensure reliable and economic grid operations and planning, support of large-scale renewable energy integration and, eventually, making for a low-carbon grid system. However, because the main purpose of batteries in BDEVs is to support travel, this would make it more complicated than stationary storage, and would require dynamic decision-making tools to evaluate the tradeoffs and optimize the benefits. New modeling and decision tools must be integrated into existing grid management software as well as BDEV management software, DMS 
and/or DERMS to support the application of BDEVs in all use cases, in order to overcome the barriers of large-scale adoption and grid integration.

\section{REFERENCES}

18 Code of Federal Regulations (CFR), Part 35. 2020. "FERC Order 2222: Participation of Distributed Energy Resource Aggregations in Markets Operated by Regional Transmission Organizations and Independent System Operators." Available at https://www.ferc.gov/sites/default/files/2020-09/E-1_0.pdf, accessed March 24, 2021.

Akhil, A.A., G. Huff, A.B. Currier, J. Hernandez, D. Bender, B.C. Kaun, D. Rastler, S.B. Chen, A.L. Cotter, D.T. Bradshaw, and W.D. Gauntlett. 2013. 2013 DOE/EPRI Electricity Storage Handbook. Sandia National Laboratory: Albuquerque, NM. Available at https://www.sandia.gov/ess-ssl/lab-pubs/doeepri-electricity-storage-handbook/.

American Gas Association. 2019. “Average Residential Gas Bills by State.” Available at https://www.aga.org/research/data/prices/.

Andoni, M., V. Robu, D. Flynn, S. Abram, D. Geach, D. Jenkins, P. McCallum, and A. Peacock. 2019. "Blockchain technology in the energy sector: A systematic review of challenges and opportunities," Renewable and Sustainable Energy Reviews 100:143-174. Available at https://doi.org/10.1016/j.rser.2018.10.014.

Blum, A.F., and T. Long Jr. 2016. Hazard Assessment of Lithium Ion Battery Energy Storage Systems. Prepared by Exponent, Inc., for Fire Protection Research Foundation: Quincy, MA. Available at https://www.nfpa.org/-/media/Files/News-and-Research/Fire-statistics-andreports/Hazardous-materials/RFFireHazardAssessmentLithiumIonBattery.ashx.

Burnham, A., D. Gohlke, L. Rush, T. Stephens, Y. Zhou, M.A. Delucchi, A. Birky, C. Hunter, Z. Lin, S. Ou, F. Xie, C. Proctor, S. Wiryadinata, N. Liu, and M. Boloor. 2021. Comprehensive Total Cost of Ownership Quantification for Vehicles with Different Size Classes and Powertrains, ANL/ESD-21/4. Argonne National Laboratory: Lemont, IL. Available at https://www.osti.gov/biblio/1780970-comprehensive-total-cost-ownership-quantificationvehicles-different-size-classes-powertrains.

Briones, A., J. Francfort, P. Heitmann, M. Schey, S. Schey, and J. Smart. 2012. Vehicle-to-Grid (V2G) Power Flow Regulations and Building Codes Review by the AVTA, INL/EXT-12-26853. Idaho National Laboratory: Idaho Falls, ID. Available at https://www.energy.gov/sites/prod/files/2014/02/f8/v2g_power_flow_rpt.pdf.

Brown, G. 2017. "Making Sense of Demand Charges: What Are They and How Do They Work?" June, 2017. https://www.renewableenergyworld.com/wind-power/making-sense-ofdemand-charges-what-are-they-and-how-do-they-work/\#gref 
California Public Utilites Commission. 2020. FINAL REPORT OF THE CALIFORNIA JOINT AGENCIES VEHICLE-GRID INTEGRATION WORKING GROUP, June 2020.

https://gridworks.org/wp-content/uploads/2020/09/GW VehicleGrid-Integration-Working-Group.pdf

Ciampoli, P. 2021. "Public Power Utilities, Others Pursue Vehicle-To-Grid Opportunities," February 1. American Public Power Association. Available at https://www.publicpower.org/periodical/article/public-power-utilities-others-pursue-vehiclegrid-opportunities.

Curtis, T.L., L. Smith, H. Buchanan, and G. Heath. 2021. A Circular Economy for Lithium-Ion Batteries Used in Mobile and Stationary Energy Storage: Drivers, Barriers, Enablers, and U.S. Policy Considerations, NREL/TP-6A20-77035. National Renewable Energy Laboratory: Golden, CO. Available https://www.nrel.gov/docs/fy21osti/77035.pdf.

Davis, S.C., and R.G. Boundy. 2020. Transportation Energy Data Book, Edition 38, ORNL/TM2019/1333. Oak Ridge National Laboratory: Oak Ridge, TN. Available at https://tedb.ornl.gov/wp-content/uploads/2021/02/Edition38_Full_Doc.pdf. .

Dominion Energy. 2020. "Electric School Buses" June 18. Available at https://www.dominionenergy.com/our-stories/electric-school-buses, accessed on March 24, 2021.

Dieziger, D. 2000. "Saving Money by Understanding Demand Charges on Your Electric Bill," December. U.S. Department of Agriculture, Forest Service, Technology \& Development Program 7100. Available at https://www.fs.fed.us/t-d/pubs/htmlpubs/htm00712373/index.htm.

Edwards, T., and M. Landi. 2018. "G2G Global Roadtrip: Around the World in 50 Projects," October. Everoze Partners Limited.: Bristol, United Kingdom. Available at https://everoze.com/v2g-global-roadtrip/, accessed on February 12, 2021.

EIA (Energy Information Administration). 2015. "2015 RECS Survey Data,” Residential Energy Consumption Survey (RECS). Available at https://www.eia.gov/consumption/residential/data/2015/.

Ferber, D. 2017. "Vehicle-To-Grid: A New Spin On Car Payments," October 31, 2011, updated June 14, 2017. Pacific Standard. Available at https://psmag.com/environment/vehicle-to-grid-anew-spin-on-car-payments-36697, accessed on March 24, 2021.

Fermata Energy. 2020. "Proven Results and Cost Savings with V2G Technology," October 12. Charlottesville, VA. Available at https://www.fermataenergy.com/news-press/proven-resultsand-cost-savings-with-v2g-technology, accessed on March 4, 2021.

Fitzgerald, G., Mandel, J., Morris, J., and Touati, H. 2015. "The Economics of Battery Energy Storage: How multi-use, customer-sited batteries deliver the most services and value to customers and the grid," Rocky Mountain Institute, September 2015. 
Guo, Z.M., Z. Zhou, and Y. Zhou. 2019. "Impacts of Integrating Topology Reconfiguration and Vehicle-to-Grid Technologies on Distribution System Operation," IEEE Transactions on Sustainable Energy 11(2):1023-1032.

GMP (Green Mountain Power). 2020. "GMP Saves Money for Customers with V2G," December 3. Available at https://greenmountainpower.com/gmp-saves-money-for-customerswith-v2g/, accessed on March 24, 2021.

IEA (International Energy Agency). 2019. Global EV Outlook 2019: Scaling-up the Transition to Electric Mobility. Available at https://www.iea.org/reports/global-ev-outlook-2019.

Kelly, J.C., and O. Winjobi. 2020. "Battery Second Life: A Review of Challenges and Opportunities." Proceedings of 33rd World Electric Vehicle Symposium and Exhibition. Portland, OR, June 14-17, 2020. Available at https://zenodo.org/record/4025444\#.YFvJO69KiUk.

Janfeshan, K., M.A.S. Masoum, and S. Deilami. 2014. "V2G application to frequency regulation in a microgrid using decentralized fuzzy controller," Proceedings of 2014 International Conference on Modelling, Identification \& Control. IEEE: Melbourne, VIC, Australia, December 3-5, 2014. doi: 10.1109/ICMIC.2014.7020781. Available at https://ieeexplore.ieee.org/document/7020781.

Malmgren, I. 2016. "Quantifying the Societal Benefits of Electric Vehicles," Proceedings of EVS29 Symposium. Montréal, QC, Canada, June 19-22, 2016. Available at https://www.mdpi.com/2032-6653/8/4/996/pdf.

McLaren, J., N. Laws, K. Anderson, and S. Mullendore. 2017. "Identifying Potential Markets for Behind-the-Meter Battery Energy Storage: A Survey of U.S. Demand Charges." National Renewable Energy Laboratory: Golden, CO. Available at https://www.nrel.gov/docs/fy17osti/68963.pdf.

Mercure, M. 2021. "Blue Bird Delivers North America's First V2G-Capable Electric School Bus," March 24, NGT News. Next-Gen Transportation. Available at https://ngtnews.com/bluebird-delivers-north-americas-first-v2g-capable-electric-school-bus, accessed on April 9, 2021.

Montoya, M., Sherick, R., Haralson, P., Neal, R., Yinger, R. 2013. "Islands in the Storm, Integrating Microrids into the Larger Grid," IEEE Power \& Energy, 2013.

NEMA Communication. 2016. Powering Microgrids for the 21st-Century Electrical System, https://www.nema.org/standards/view/powering-microgrids-for-the-21st-century-electricalsystem.

NFPA (National Fire Protection Association). 2020. NFPA 855 Standard for the Installation of Stationary Energy Storage Systems, 2020 Edition. 
NREL (National Renewable energy Laboratory). 2020. "Blockchain: Not Just for Bitcoin," May 14. Golden, CO. Available at https://www.nrel.gov/news/features/2020/blockchain-not-justfor-bitcoin-nrel-researchers-demonstrate-collaborative-energy-transactions.html.

Proffitt, A. 2020. “Argonne National Labs Using AI To Predict Battery Cycles,” August 3. AI Trends: The Business and Technology of Enterprise AI. Available at https://www.aitrends.com/ai-research/argonne-national-labs-using-ai-to-predict-battery-cycles/, accessed on February 25, 2021.

Schoup, D. 2017. The High Cost of Free Parking, updated edition. Routledge: New York, NY.

SEPA (Smart Electric Power Alliance). 2019. A Comprehensive Guide to Electric Vehicle Managed Charging. May, 2019.

SEPA (Smart Electric Power Alliance). 2020. A Regulatory Roadmap for Vehicle-Grid Integration. December 2020.

Singh, P. 2021. "Blockchain Powered LO3 Energy Gets \$11 Million For Distributed Energy Marketplace," updated March 15. Saur Energy International. Available at https://www.saurenergy.com/solar-energy-news/blockchain-powered-lo3-energy-gets11-millionfor-distributed-energy-marketplace.

Traywick, C., M. Chediak, N. Malik, and J. Soul. 2021. "The Two Hours That Nearly Destroyed Texas's Electric Grid," February 20. Bloomberg Green. Available at https://www.bloomberg.com/news/features/2021-02-20/texas-blackout-how-the-electrical-gridfailed, accessed April 25, 2021.

Virta. 2021. "Virta for Energy Companies.” Available at https://www.virta.global/energycompanies, accessed on March 24, 2021.

Warmerdam, J., J. van der Hoogt, and R. Kotter. 2020. Final Report - Johan Cruijff ArenA Operational Pilot. European Regional Development Fund, Interreg North Sea Region, SEEV4City. Available at https://www.seev4-city.eu/wp-content/uploads/2020/10/SEEV4-City-JohanCruijff-ArenA-Operational-Pilot-Final-Report.pdf.

Zhou, Z., Levin, T., and Conzelmann, G. 2016 "Survey of U.S. Ancillary Services Markets," Argonne National Laboratory, ANL/ESD-16/1, Jan. 2016. Available at https://publications.anl.gov/anlpubs/2016/09/130102.pdf 



\section{Argonne}

\section{Energy Systems Division}

Argonne National Laboratory

9700 South Cass Avenue, Bldg. 362

Lemont, IL 60439-4832

www.anl.gov 